\title{
IFCInfra4OM: An Ontology to Integrate Operation and Maintenance Information in Highway Information Modelling
}

\author{
Sara Ait-Lamallam ${ }^{1, *(1)}$, Imane Sebari ${ }^{1}\left(\mathbb{D}\right.$, Reda Yaagoubi $^{1}\left(\right.$ and Omar Doukari $^{2}$ \\ 1 School of Geomatics and Surveying Engineering, Hassan II Institute of Agriculture and Veterinary Medicine, \\ Rabat 10112, Morocco; i.sebari@iav.ac.ma (I.S.); r.yaagoubi@iav.ac.ma (R.Y.) \\ 2 Department of Mechanical \& Construction Engineering, Northumbria University, \\ Newcastle-Upon-Tyne NE1 8ST, UK; omar.doukari@northumbria.ac.uk \\ * Correspondence: s.aitlamallam@iav.ac.ma
}

Citation: Ait-Lamallam, S.; Sebari, I.; Yaagoubi, R.; Doukari, O IFCInfra4OM: An Ontology to Integrate Operation and Maintenance Information in Highway Information Modelling. ISPRS Int. J. Geo-Inf. 2021, 10, 305. https://doi.org/10.3390/ ijgi10050305

Received: 3 March 2021

Accepted: 2 May 2021

Published: 6 May 2021

Publisher's Note: MDPI stays neutral with regard to jurisdictional claims in published maps and institutional affiliations.

Copyright: (c) 2021 by the authors. Licensee MDPI, Basel, Switzerland. This article is an open access article distributed under the terms and conditions of the Creative Commons Attribution (CC BY) license (https:// creativecommons.org/licenses/by/ $4.0 /)$.

\begin{abstract}
Building information modelling (BIM) is increasingly appropriate for infrastructure projects, and in particular for transport infrastructure. It is a digital solution that integrates the practices of the construction industry in facility management during the whole life cycle. This integration is possible through a single tool, which is the 3D digital model. Nevertheless, BIM standards, such as industry foundation classes, are still in the pipeline for infrastructure management. These standards do not fully meet the requirements of operation and maintenance of transport infrastructure. This paper shows how BIM could be implemented to address issues related to the operation and maintenance phase for transport infrastructure management. For this purpose, a new ontological approach, called Industry Foundation Classes for Operation and Maintenance of Infrastructures (IFCInfra4OM), is detailed. This ontology aims to standardise the use of building information modelling for operation and maintenance in road infrastructures. To highlight the interest of the proposed ontological approach, a building information model of a section on the A7 Agadir-Marrakech Highway in Morocco is produced according to IFCInfra4OM. The methodology is presented. The results obtained, including the IFCInfra4OM data model, are submitted. In the last section, an overview of the IFC extension approach is submitted.
\end{abstract}

Keywords: building information modelling; operation and maintenance; transport infrastructures; road; industry foundation classes (IFC); ontological approach; standard

\section{Introduction}

Building Information Modelling (BIM) is a collaborative process for managing construction projects. It has several advantages that enable an optimisation of the management process. Practically, BIM is a digital solution that integrates the different practices of the construction industry to manage a facility during its life-cycle [1]. This integration is attainable through a single paradigm, namely the 3D digital model [2], which provides an overview of BIM and its applications during the life cycle of a building. It also explains its benefits for stakeholders of a construction project through case studies.

Construction projects have become more efficiency-demanding because of their complexity [3]. They focus on user experience [4,5]. Accordingly, the BIM paradigm is considered as a digital solution that integrates the business processes in a comprehensive system that makes information accessible and transmissive. Exchanging information occurs ranging from the early design stages of a building's life cycle to its investment phase [6]. The BIM process displays this exchange by the integration of basic semantics to structure information relevant to all the phases throughout a building's life cycle. This information has to meet the requirements of different use cases that correspond to each specific phase [7].

The application of BIM in the building construction sector helps optimising the management of each building life-cycle phase. For example, it can help reduce building 
environmental impact through its 3D capabilities of representing a wide range of construction design options [8]. Moreover, construction site conditions can be improved through space-time conflicts detection and analysis based on the use of BIM [9]. Furthermore, building management and performance can be improved if the BIM is used within operation and maintenance $(\mathrm{O} \& \mathrm{M})$ phase of the building [10].

The BIM has several advantages reported in the building industry [11,12] such as: (1) decrease of work resumption thanks to early error detection, particularly in the design phase; (2) decrease in information inquiry that spares valuable time; (3) increasing collaboration between projects stakeholders; (4) sustainment of a continuous flow of information exchange during the whole building life-cycle. The application of BIM is contingent upon several standards. Industry foundation classes (IFC) [13] constitute one of these standards. IFC is an object-oriented data architecture that enables geometry data and information of a construction project to be structured in a standardised way [14]. Figure 1 is an illustration of the link between BIM and IFC standard. BIM is a collaborative process for construction projects management that integrates technology, construction stakeholders and management workflows. This allows transforming projects inputs to an IFC structured 3D model that holds the project information and its components geometry.

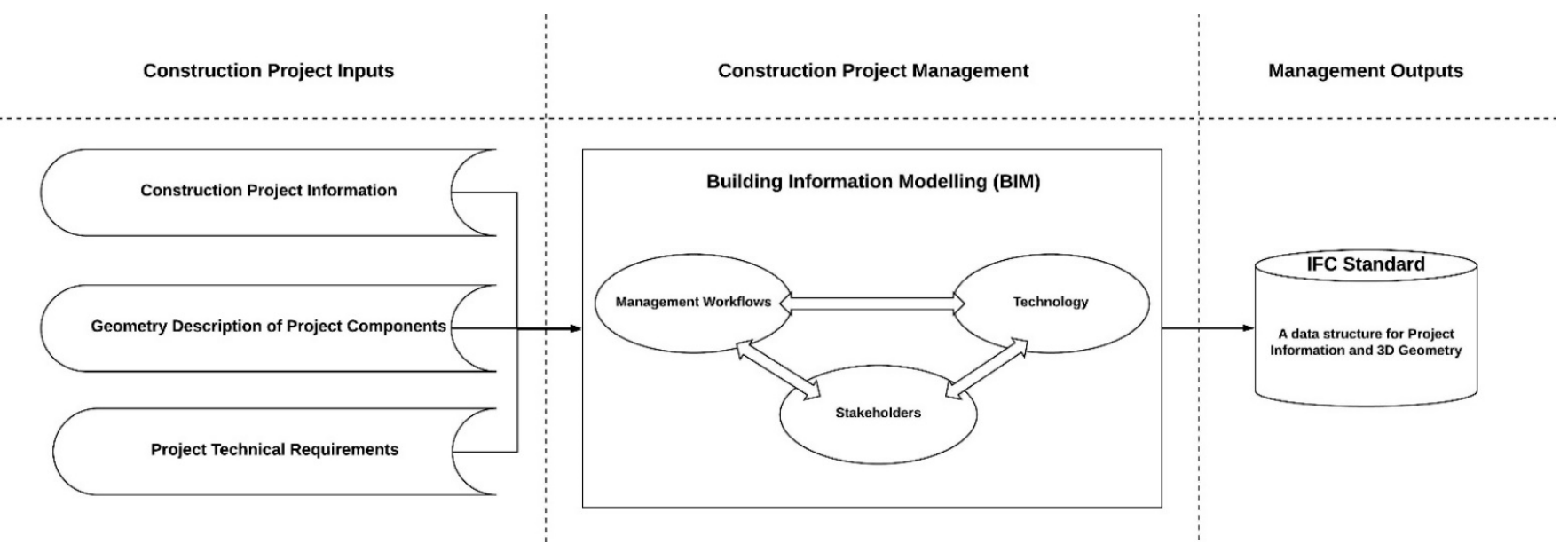

Figure 1. Relation between BIM and IFC standard.

BIM advantages have enabled it to expand from the building sector to that of infrastructure. Several papers detail the application of BIM to infrastructure. The implementation of BIM for transport infrastructures is analysed in [15]. It explains how BIM can be beneficially used for public infrastructure construction projects. For bridges, BIM is applied in risk management by linking risk data to a steel bridge BIM [16]. A BIM based design of a tunnel is presented in [17]. It integrates geotechnical information to a three-dimensional subsoil model to enable project stakeholders to perform analysis of deformation. For road infrastructures, the optimisation of pavement design is accomplished through BIM [18]. An automation approach is proposed to allow pavement structure analysis of the BIM through an integration of controllable parameters.

For highway infrastructure, the integration of BIM is not yet applicable to all its life cycle phases. This is due to the fact that BIM Standards, for infrastructures, are still in development $[19,20]$. Nowadays, infrastructures are managed through several systems from which information is retrieved to make appropriate decisions about O\&M. However, a standardised highway information model integrating O\&M information is not yet possible to produce since the current IFC structure does not allow a full support. Thus, this paper proposes a novel ontological approach, entitled Industry Foundation Classes for Operation and Maintenance of Infrastructures (IFCInfra4OM), to integrate O\&M information in a highway information model. It first investigates how O\&M phase is managed within transport infrastructures, in Sections 1 and 2, and how BIM can help optimise it. In 
Section 3, the methodology and materials are elaborated. Section 4 is dedicated to the IFCInfra4OM ontology and its data model. The implementation of the IFCInfra4OM through the Moroccan A7 Highway section BIM is detailed in Section 5. It also provides an overview of results validation methods. The approach of extending the BIM standard with the IFCInfra4OM ontology is synthesised in Section 6 and further insights on future work are proposed in the last section.

\section{Literature Review}

BIM helps to resolve management issues through a whole life cycle of a facility [11]. However, its integration is more intensive for conception and construction phases than for O\&M [21]. Moreover, its standardised applicability for transport infrastructures is limited. On the one hand, these facilities are more complex [22] than buildings and there are several system types to manage them. On the other hand, the data structure of the BIM Standard, namely IFC, does not fully meet the transport infrastructures O\&M requirements.

\subsection{Operation and Maintenance for Transport Infrastructures}

The O\&M phase of a facility's life cycle includes day-to-day activities to maintain its intended function and environment. Further, the terms Operation and Maintenance are combined in the appellation of this phase because a facility cannot operate at peak efficiency without being maintained [23]. It is considered as the most expensive phase in the whole life cycle of an infrastructure facility [24]. Its high costs are caused either by: (1) The long duration of O\&M phase; (2) the use of unsuitable O\&M methods [22]; or (3) the failure of taking into account the characteristics of each infrastructure [25]. This involves additional costs in the O\&M phase to collect and recreate useful information [11].

There are multiple computer aided management systems to hold this phase. These systems help maximising O\&M management for infrastructures through the integration of several information about the facility and its environment. Examples of these systems are detailed in Table 1. These systems integrate several information about: (1) daily process: routine operations to maintain optimal functioning of a facility; (2) emergency process: pre-defined protocols that manage untoward events in the future [26]; and (3) statutory inspection [27]: including mandatory inspection and preventive maintenance.

Table 1. Examples of Computer Aided Management Systems for Transport Infrastructures.

Computer Aided Management System
Computerized Maintenance Management Systems (CMMS)

They are digital systems that integrate equipment inventory and ordered maintenance operations of a facility to help its daily management $[23,28]$.

Building Automation Systems (BAS)

They are networks of electronic devices designed to control all systems in a construction (lighting, fire, security, HVAC ... ) in order to keep its environment in a defined range and to optimise its maintenance [29].

They are defined in [30] as a complete system that assimilate all

Integrated Work- place Management Systems (IWMS) strategic and operational systems of a facility to allow its efficient functioning on quality, environment, health and security levels.

They are systems that enable an optimisation of travel experience for transport infrastructures users [31,32]. A relevant

Intelligent Transport Systems Management example is Real-Time Crowding Systems that improve travel conditions by collecting real-time data on passenger flows and crowding levels from multiple sources [31].

They are systems based on several telecommunication technologies and application processes. They guaranty the safety of transport system and its environment. These systems

Transport Safety Systems integrate multisource data to enable danger prevention [33]. 
Infrastructure facilities are characterised by different economic, environmental and political specificities that are more complex than buildings [34,35]. For these facilities to be fully operational, they require particular type of information to be integrated in their management system [36]. This information can be summarised as illustrated in Table 2.

Extensive efforts have been deployed to manage systems that integrate the various types of information mentioned in Table 2, but these systems are linked to several databases which makes them difficult to access and to re-use [37]. Furthermore, using these systems can cause information redundancy problems. Moreover, insufficient training for users leads to manual entries that can make the system information redundant or erroneous [23]. Finally, experts in O\&M, for infrastructures are not involved in the earliest phase of a project, namely the design phase [22], which results in a lack of data in the system, an inconsistency, or even improper data.

Table 2. O\&M Requirements for Infrastructure Facilities.

\begin{tabular}{cl}
\hline Information Type & \multicolumn{1}{c}{ Its Definition [36,38] } \\
\hline Project information & it represents legal and financial data of the facility. \\
\hline Asset's information & it traces geometric and functional information about objects and equipment subject to O\&M. \\
\hline Operating information & $\begin{array}{l}\text { it includes real-time collected data by a monitoring system or an operating human to insure } \\
\text { statutory inspection process. }\end{array}$ \\
\hline Safety information & it allows automatic notifications to inform in case of emergency problem. \\
\hline Performance information & they are the indicators that help analyse activities efficiency. \\
\hline Stakeholders' information & it allows automatic notifications to inform in case of emergency problem. \\
\hline
\end{tabular}

\subsection{BIM and OEM for Transport Infrastructures}

\subsubsection{BIM for O\&M Management}

According to the National Institute of Standards and Technologies of the United States report [39], the regression in the construction sector was estimated at $30 \%$ compared to other industries over the last 40 years. In the same report, this regression is due to a lack of interoperability and scarcity of software solutions. BIM is the answer to address these issues. However, its scope of application within the entire life cycle of a facility is restricted to the inception of the project [40].

BIM has been appropriated in transport infrastructures because of its ample advantages. Some examples of studies supporting these advantages are: (1) The investigation conducted in [41] that compared two bridge construction processes. One of these processes includes BIM which consequently results in an optimisation of the costs, request for information (RFI) and change order information (CO) indexes; and (2) a study by Cheng et al. [42] that analyses the uses of BIM for infrastructures and its function throughout all life-cycle phases. This shows how BIM application for transport infrastructures is restricted in the O\&M phase.

The objective of BIM is to reduce prelims the effort of collecting and creating data concerning the entire life cycle of an infrastructure [43] to avoid problematic issues that may arise in late phases such as O\&M. Several innovative applications to integrate BIM to solve O\&M issues, are carried out. Examples of these applications are: (1) decision-making and communication improved by the integrated case-based reasoning (CBR) to a BIM system [44]. It allows retrieving asset maintenance history by linking a BIM model with a professional knowledge base; (2) integration of a BIM model with a CMMS [45]. This study gives opportunity to improve operational phase management through early collaboration between designer and facility management team through linking operation information with a BIM; (3) risk analysis in a tunnel construction operation using BIM [46,47]. Tunnel 3D model is extended to support additional semantic information related to operations and to ground conditions; (4) diagnostics and tractability improvement by objects inspection automated using BIM [48]. The IFC files are analysed using algorithm in the aim to update 
objects properties and geometry with results of inspection; (5) improving Emergency process using BIM [1]; and (6) preventive maintenance optimisation using a BIM facility management system [38]. It is realised through updating equipment failures and linking them to maintenance works on a BIM model.

Considering standardisation, the Information Delivery Manual (IDM) standard (ISO 29481) [49] developed by BuildingSmart [50] can be a substructure for integrating O\&M in BIM. IDM is a methodological process map in which each process relates to an activity. Every one of these processes is represented as a step-by-step workflow with definition of stakeholders and data exchange at each step. IDM was converted to a data model in [51] to be linked with an asset information model to manage a facility database system.

\subsubsection{O\&M Information Integration Issues in BIM Standard}

All these previously mentioned approaches are based on a linking of several systems processes. However, the application of standardised BIM needs to consider the integration of O\&M information in the BIM standards such as the industry foundation classes (IFC). In fact, decisions issued in an O\&M process are affected by hierarchical connections between the BIM objects [21]. This consideration cannot be realised through the approaches discussed above for several reasons. First, they link a BIM model with extra information systems with non-topological rules. Second, the BIM model is used as a 3D visualisation tool where information is added to objects separately, do not respect a predefined use case's map in BIM process management.

The limitations of integrating O\&M in IFC schema for transport infrastructures are mainly due to:

1. Infrastructure IFC schemata that are still under development [52]. For example, The IFCBridge project has reached the implementation phase since March 2019 [19], while the IFCRoad has been released as a prototype data model since July 2019 [20]. These two schemata are more oriented to manage conception and construction phase. It is perhaps primordial for an infrastructure but do not represent the whole life cycle.

Another issue that concerns the current IFC version is that the existing O\&M information are well structured in the IFC schema, but are not enough to manage this whole phase for transport infrastructure [48]. This information concern [52,53] risk information, warranty, service life, condition, manufacturer, environmental impact, and work control. On the one hand, this information is not complete [21,52]. There are limitations in describing general organisational functions, such as financial management and risk management [54]. Furthermore, information to describe system optimisation performance and energy requirements are not integrated into the IFC schema [52]. On the other hand, information about O\&M in IFC schema do not allow a complete management of the O\&M process for infrastructures. In fact, supporting a complete O\&M process is done through sufficient relations between O\&M object classes that exist in the IFC schema. While studying the IFC standard, it is noticed that interactions between actors and space management programs are not supported [55]. All these gaps make the O\&M process requirements for infrastructures not fully supported by the BIM Standard. These requirements are, first, all information types that allows an optimal O\&M process management. They are already described in Section 2.1. Second, complete interactions between O\&M data within the IFC schema are part of these requirements. The main objective of this paper is to present a new ontological approach to solve these two impeding issues of O\&M integration in BIM for Highway Infrastructure as a particular example of transport infrastructures. The main advantage of using an ontological approach is that it defines concepts constituting a domain of knowledge and determines representations and structures of objects, properties, events, processes, and relations in physical reality [56]. It is, in fact, relevant for a standardisation process to produce definitions and allow a universal use.

Our research contribution is a proposition of a data model called IFCInfra $4 \mathrm{OM}$ that serves to bridge the gaps studied in the literature review. This data model, constructed 
through an ontological approach, structures information requirements of a highway O\&M phase. It allows:

1. Hierarchical relations between O\&M data in accordance with real technical O\&M process. This solves the issue of non-structured O\&M information in the IFC schema.

2. Identification of O\&M requirements to fully manage such a phase for highway infrastructures. This definition is based on international standards and technical documents as reported in Section 3.1.

3. Extension of the IFC standard through the schema reported in Section 6. This enables standardised BIM to be applied to highway infrastructures instead of BIM-external systems linking. It allows the highway information model to be the only database shared to manage all project data through the O\&M phase.

\section{Materials and Methods}

\subsection{Materials}

To build the IFCInfra4OM ontology, several documents inspired our research: (1) basic scientific articles; (2) norms and standards; as well as (3) technical documents published by expert organisations. These documents are detailed in Table 3 . They first provide an explanation of the type of information required to successfully complete an O\&M process. Then, their analysis allows us to decide on the concepts to define for this ontology. Finally, they help to determine the highway objects to which the defined concepts must be linked.

Table 3. Base Material for Constructing IFCInfra4OM Methodology.

\begin{tabular}{cr}
\hline Base Document & Knowledge Domain \\
\hline ISO 55000 standard [57] & Asset Management (transport infrastructures included) \\
\hline PAS 1192-3 standard [58] & BIM and O\&M for Building \\
\hline EurOTL Ontology [59] & Road Asset Information Management \\
\hline $\begin{array}{c}\text { BSI technical report on the requirements of infrastructure } \\
\text { managers in a BIM process [60] }\end{array}$ & BIM and Infrastructure Asset Management \\
\hline $\begin{array}{c}\text { Morocco Highway Organization (ADM) technical documents } \\
\text { [61-65] }\end{array}$ & Highway Infrastructure and O\&M \\
\hline LandInfra standard (OGC) [66] & BIM and Transport Infrastructures
\end{tabular}

After investigating these materials, three categories prevail. First, some norms are relevant to information requirements of different kinds of facilities which makes information vague, all-inclusive and imprecise. Second, other norms facilitate the management of the investment phase. Information can then be relevant to any stage of investment phase such as O\&M, demolition or renovation stage. Finally, some standards apply to all transport infrastructures and not just for roads or more specifically highways. However, their study helps define the semantics that can be added to BIM objects to allow an efficient highway O\&M management.

The management of the O\&M phase for highways is based on several asset management (AM) practices and BIM can significantly help optimise them [67]. According to these practices, the IFCInfra4OM ontology is defined in compliance with the main rules integrated into an AM system, namely:

- Compliance: This represents the measure of a value's conformity with a standardised value. Exceeding the normalised value leads to a problem in the process.

- Prevention: The set of actions aimed at detecting a process problem and redressing it before it occurs.

- Reliability: The measure of a process failure risk. 
- Quality: This is the process steps 'ability to meet the requirements of a smooth operation of a highway'.

The integration of these rules in the ontology made it possible to define several concepts as illustrated in Section 4.1. Besides, the definition of the concepts was also based on two criteria, namely:

- Universality: The ontology is defined in such a way as to allow an extension of the IFC standard.

- Road infrastructure management oriented: The ontology contains concepts that can be applied to the management of roads and their assets in general and not only of highways in particular. In addition, the concepts should allow the management of the O\&M phase of this type of infrastructure.

\subsection{Methodology}

The methodology for constructing the IFCInfra4OM ontology is established on four main stages. The first step is that of defining ontology. The second concerns the modelling of this ontology in order to allow its application on real world data. The third step is the validation of the data model. Finally, the fourth step aims to apply this model to a case study. This methodology is thoroughly elaborated in Figure 2.

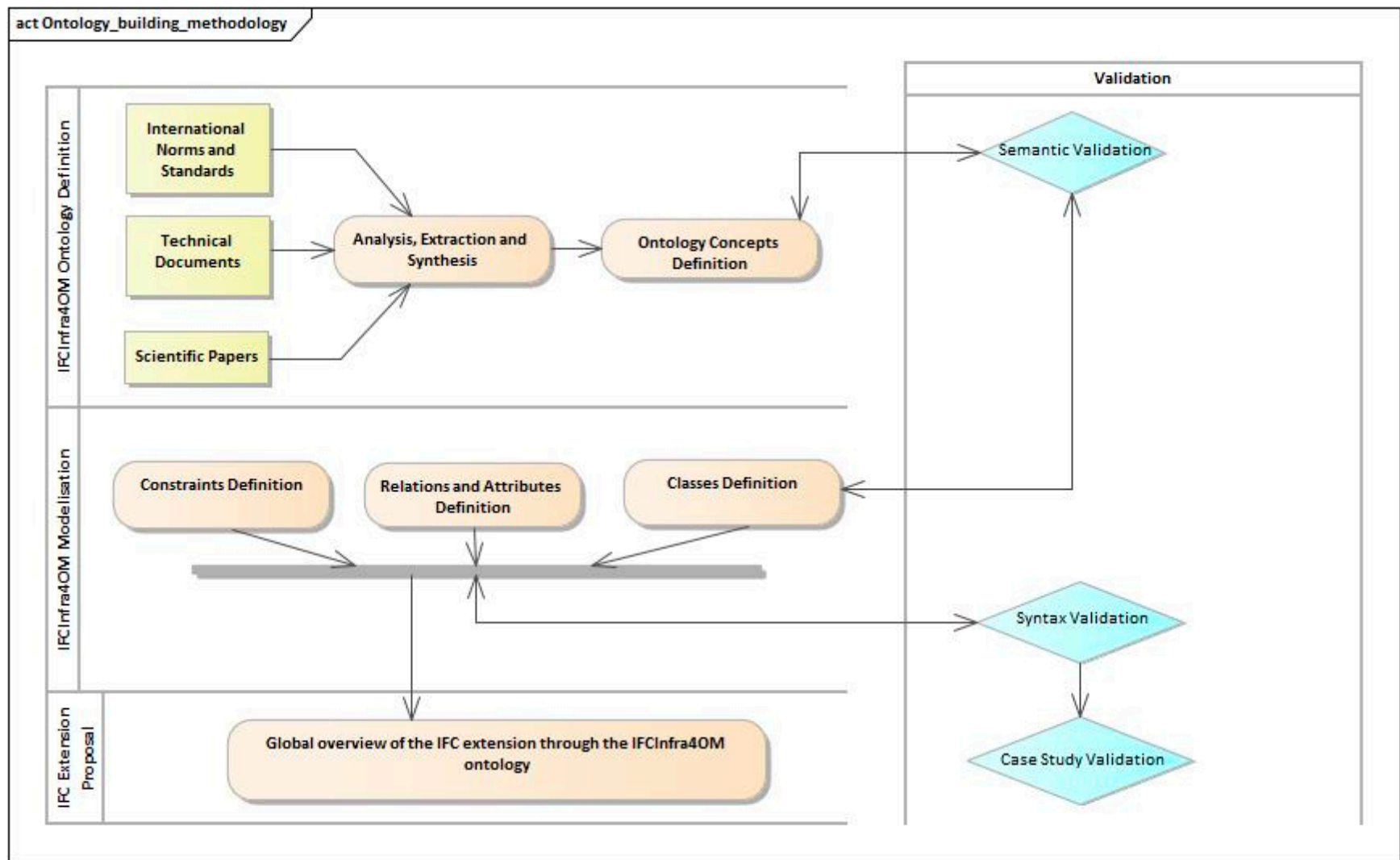

Figure 2. Constructing IFCInfra4OM Ontology Methodology.

\subsubsection{IFCInfra4OM Definition}

The IFCInfra4OM ontology is defined according to three main steps:

(1) Highway O\&M domain study: the information's needs and requirements for this phase are examined in order to define the concepts of the ontology. This step was based on: (1) the formerly introduced literature review; (2) international norms and standards relating to the O\&M phase in the field of AECs; (3) the content of the IFC standard in terms of O\&M information and (4) O\&M technical documents published 
by specialised organisations. This step led to the completion of an O\&M process for highways.

(2) Establishment of the IFCInfra4OM ontology: the concepts, their properties and relations are defined. The basic criteria for the definition of these concepts are detailed in Section 3.1. These concepts are also linked to the defined process.

(3) Extension of the IFC standard by the O\&M ontology model: this step consists of proposing an extension of the IFC standard based on the ontology data model in order to integrate the O\&M process within this standard. At this level, this step is not detailed, but an overview is provided in Section 6 .

\subsubsection{IFCInfra4OM Semantic Model}

IFCInfra4OM object-oriented modelling is based on the Unified Modelling Language (UML). The concepts are modelled in classes with a description of their properties. This modelling aims to: (1) highlight the concepts defined in the ontology; (2) integrate the main rules of an AMS; (3) allow multiple uses of the ontology by other database systems and (4) be able to provide an extension of the IFC schema.

\subsubsection{IFCInfra4OM Validation}

The IFCInfra4OM ontology is validated on the semantic level, the syntactic level and then by a case study:

(1) Semantic validation is realised with highway O\&M experts assistance. This semantic validation was executed during several working sessions to provide remarks and recommendations about concepts, their connections and attribute information.

(2) Syntactic validation is achieved to verify the conformity of the model produced with the rules of UML formalism and the conformity of the grammatical rules with the XML language.

(3) Case study validation is made by the implementation of the IFCInfra4OM data model on a segment from the A7 Agadir-Marrakech Moroccan highway. First, a database is generated from the IFCInfa4OM data model. Second, O\&M works realised on this highway segment are transcribed in the database. Third, a 3D model of the highway segment is realised. It presents the three-dimensional geometry of the segment components: pavement, traffic security equipment, digital terrain mode, and equipment installed or repaired on behalf of the O\&M works. Fourth, a mapping procedure had helped integrate O\&M information into the highway segment 3D model. This had allowed the construction of a highway information model. Finally, O\&M information reporting is retrieved from the highway information model to demonstrate practical use of the IFCInfra4OM data model.

\section{IFCInfra4OM Ontology}

\subsection{OEM Process and Ontology Definition}

The O\&M phase of a highway infrastructure is managed according to a process that includes both monitoring and intervention steps to resolve any identified problems. Monitoring steps are intended to constantly inspect the infrastructure. Inspection is done either by a field agent, according to a planner, or by a monitoring system. Emergency inspection is done when an event occurs like a traffic accident. For monitoring, two types of systems are included: (1) fixed system such as sensor networks integrated to highway components; or (2) independent equipment like terrestrial 3D scanner used to measure deformations in a highway component. Intervention steps of the process include actions to maintain, repair or replace a highway component. These actions are operations made in the field to perform either routine maintenance work or heavy maintenance work. The IFCInfra4OM ontology model, developed within the framework of this paper, is designed in such a way as to integrate the information from all these steps in a single container as illustrated by Figure 3. 


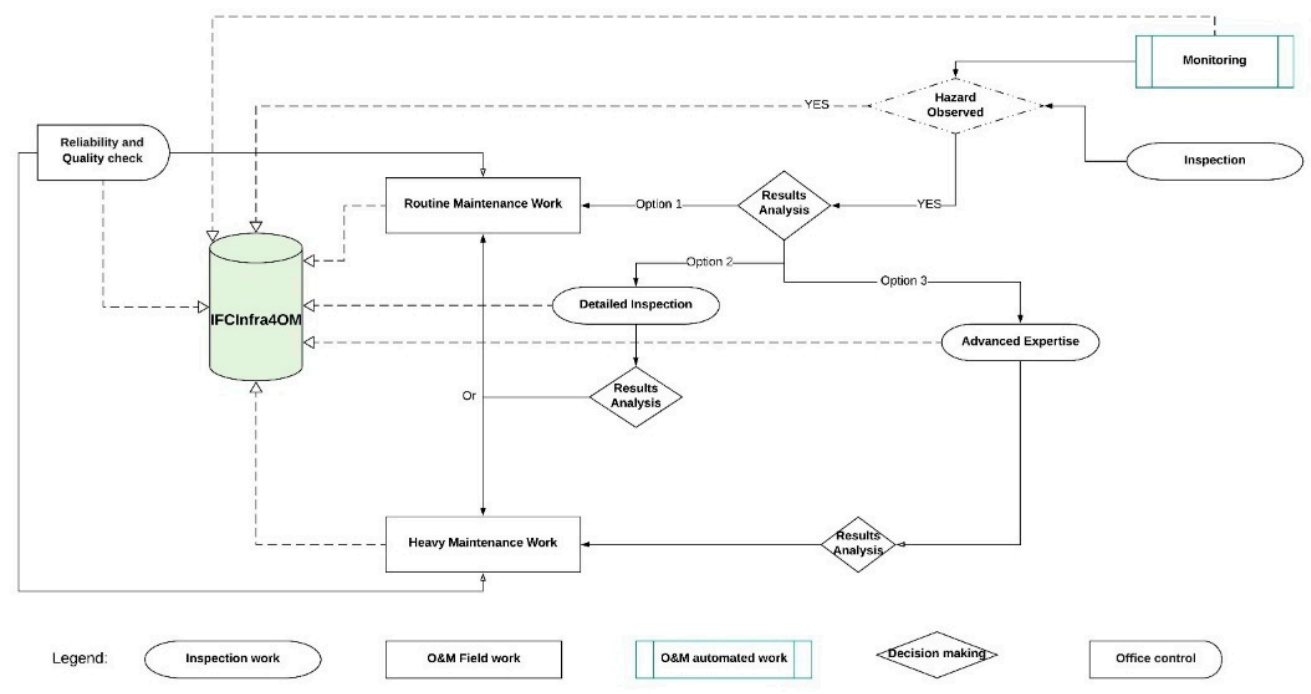

Figure 3. O\&M Process for Highway Infrastructure.

For the proper management of highway life-cycle O\&M phase, two levels of data definition exist in the ontology:

(1) Level of O\&M concepts: This concerns the O\&M phase of a highway infrastructure and incorporates the concepts necessary to describe the O\&M process.

(2) Level of Highway components: This level contains highway environmental equipment and components. This level has not been developed within the present framework because there are indeed several models in the literature to do so $[20,59,66]$. Having said that, the objective here is to model only those elements that have a direct relationship with O\&M. In fact, in Figure 4, which illustrates the diagram of the IFCInfra4OM ontology, the concepts relating to the components of a highway are modelled based on the LandInfra standard [66] to allow a first implementation of the ontology. In future work, these concepts will be replaced by the corresponding concepts on the IFC schema once extended.

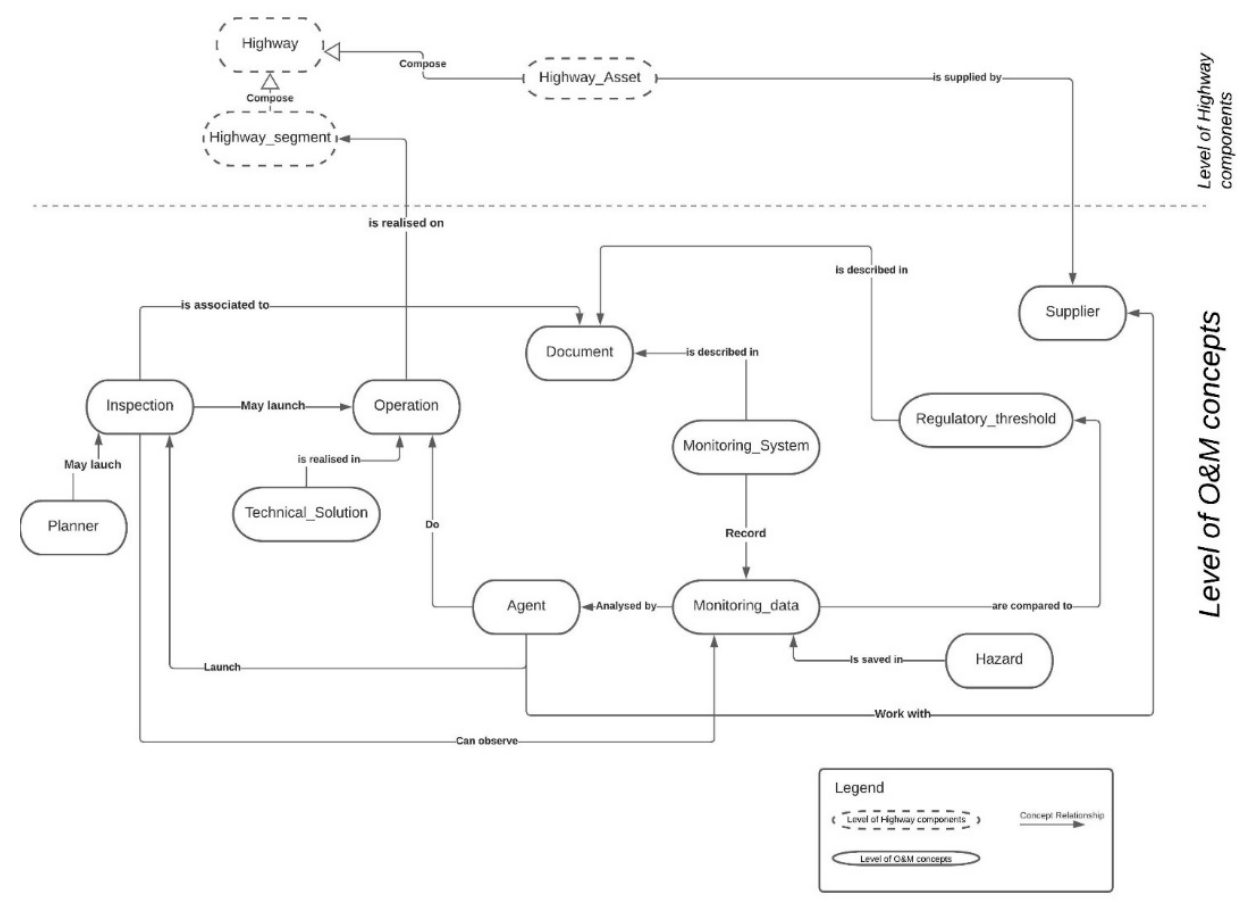

Figure 4. IFCInfra4OM Ontology Definition Schema. 
The concepts of IFCInfra4OM are of the following types: (1) objects, (2) operation, (3) event, or (4) person. Their attributes information makes it possible to understand the concept and also to integrate the AMS rules relating to the reliability and quality of the system as explained in Table 4 .

Table 4. Integrating O\&M Rules into the IFCInfra4OM Ontology.

\begin{tabular}{clll}
\hline AMS Concept & \multicolumn{1}{c}{ Rule } & Associated IFCInfra4OM Concept \\
\hline Compliance & $\begin{array}{l}\text { Exceeding the normalised value leads to the realisation of a } \\
\text { problem in the process. }\end{array}$ & $\bullet$ & $\begin{array}{l}\text { Regulated threshold } \\
\text { Risk }\end{array}$ \\
\hline \multirow{2}{*}{ Prevention } & The establishment of a monitoring system helps prevention. & $\bullet$ & $\begin{array}{l}\text { Inspection } \\
\text { Risk } \\
\text { Monitoring Data }\end{array}$ \\
\hline Reliability & $\begin{array}{l}\text { The inspection of the results of an operation after a defined } \\
\text { period of time judges its reliability. }\end{array}$ & $\bullet$ & Inspection \\
\hline \multirow{2}{*}{ Quality } & $\begin{array}{l}\text { The study of solutions proposed by an inspection judges their } \\
\text { quality.The inspection of the results of an operation after a } \\
\text { defined period of time judges its quality. }\end{array}$ & $\bullet$ & $\begin{array}{l}\text { Technical solution } \\
\text { Inspection }\end{array}$ \\
\hline
\end{tabular}

\subsection{IFCInfra4OM Data Model}

IFCInfra4OM is modelled according to the Unified Modelling Language (UML) formalism as a class diagram (see Figure $5 \mathrm{a}-\mathrm{c}$ ). Its data structure is organized into three packages: (1) Operations; (2) Monitoring and (3) Actors. It is then written in Extensible Markup Language (XML), as illustrated in Figure 6. This transcription aims to validate the syntax of the data model and to allow the future enrichment of the IFC standard. The level of development (LODt) adopted for each concept depends on its usefulness in the O\&M process, its level of data definition (O\&M or Highway Component) and its properties. For example, the concept "monitoring data" is modelled in a class of its own, while operation types are modelled as enumerations. Admittedly, each monitoring data is of a different nature and comes from a different source, whereas operations are abstract concepts that are part of the O\&M process. Table 5 describes the three LODts defined by the IFCInfra4OM ontology.

Table 5. IFCInfra4OM LODt Defined.

\begin{tabular}{ccc}
\hline LODt & IFCInfra4OM Concept Example & UML Modelling \\
\hline High & Monitoring Data & Object Class \\
\hline Medium & Replacement & Enumeration Type of the Class Object 'Operation' \\
\hline Low & Risk & Attribute of the Class 'Hazard' \\
\hline
\end{tabular}

The development of IFCInfra4OM is based on international norms and standards that have inspired the research. Actually, and for the modelling of certain concepts, some information was extracted from these standards and reused in the model, as described by Table 6.

Table 6. Information Extracted from Standards and Reused in the IFCInfra4OM Data Model.

\begin{tabular}{cccc}
\hline IFCInfra4OM Concept & Type & Origin Concept & Base Standard \\
\hline Risk & Attribute & Risk & IFC4.3 \\
Replacement & Enumeration Type & ReplacementActivity & EurOTL Standard \\
Realisation & RealisationActivity & EurOTL Standard \\
Technical Solution & TechnicalSolution & Tass & \\
\hline
\end{tabular}




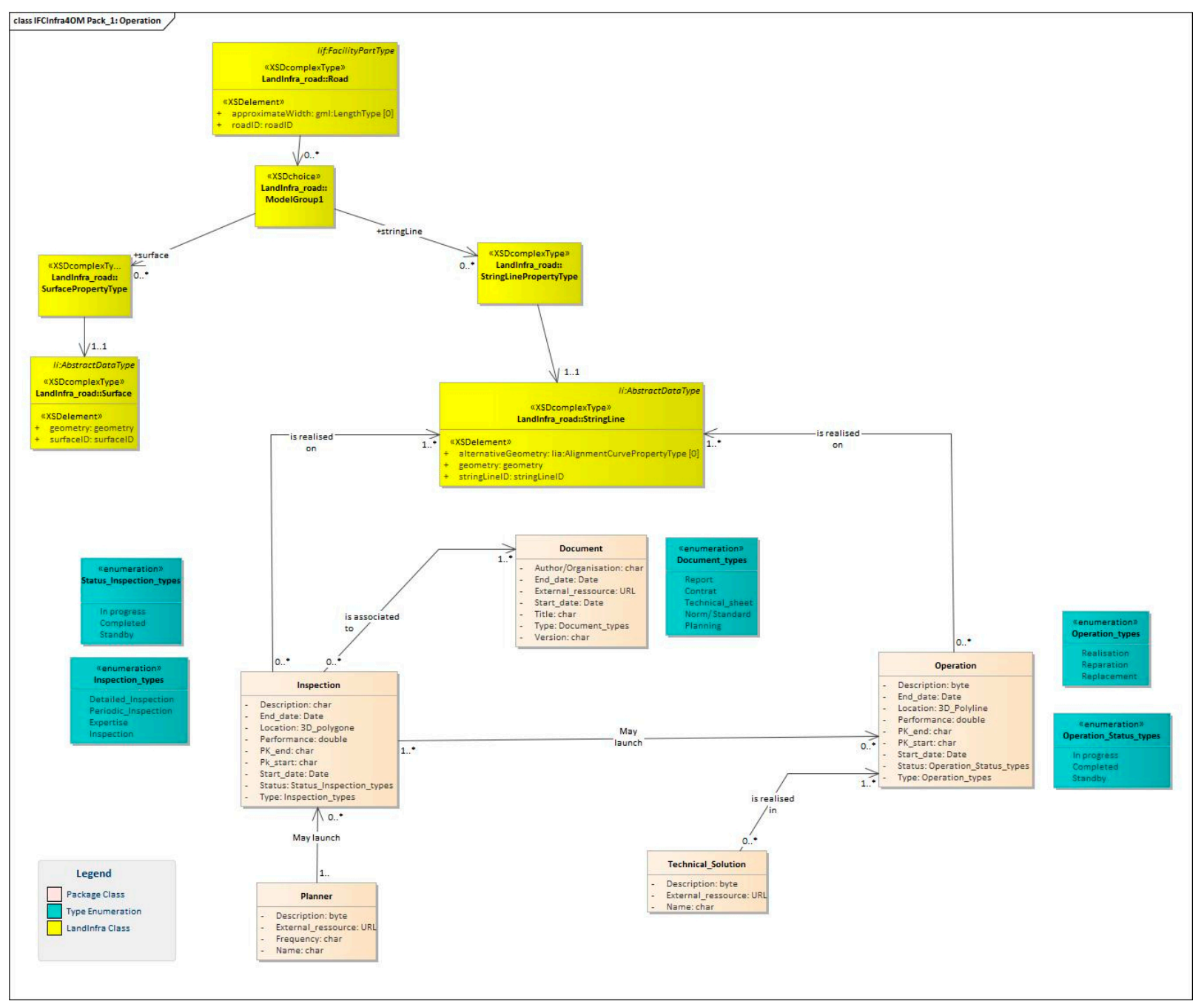

(a)

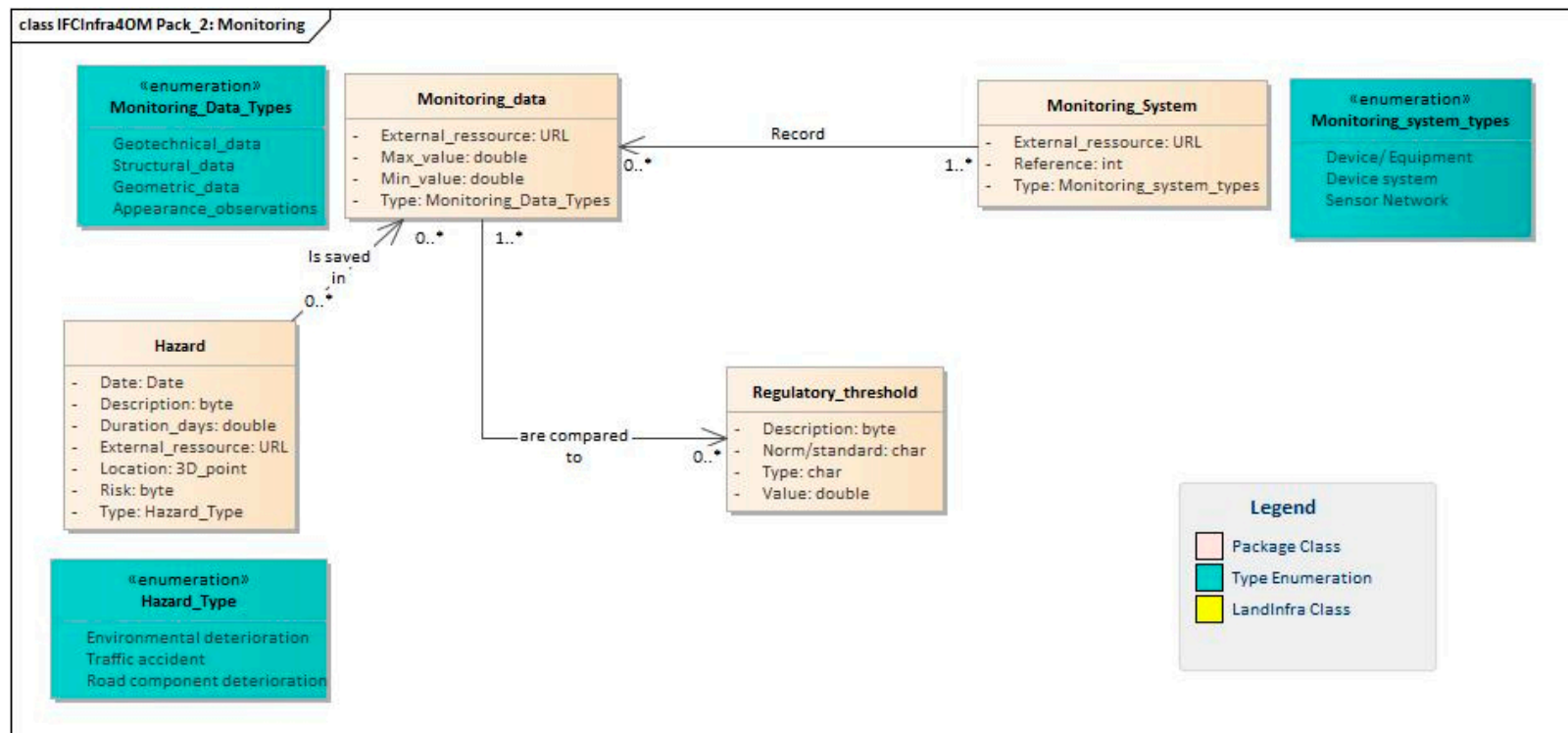

(b)

Figure 5. Cont. 


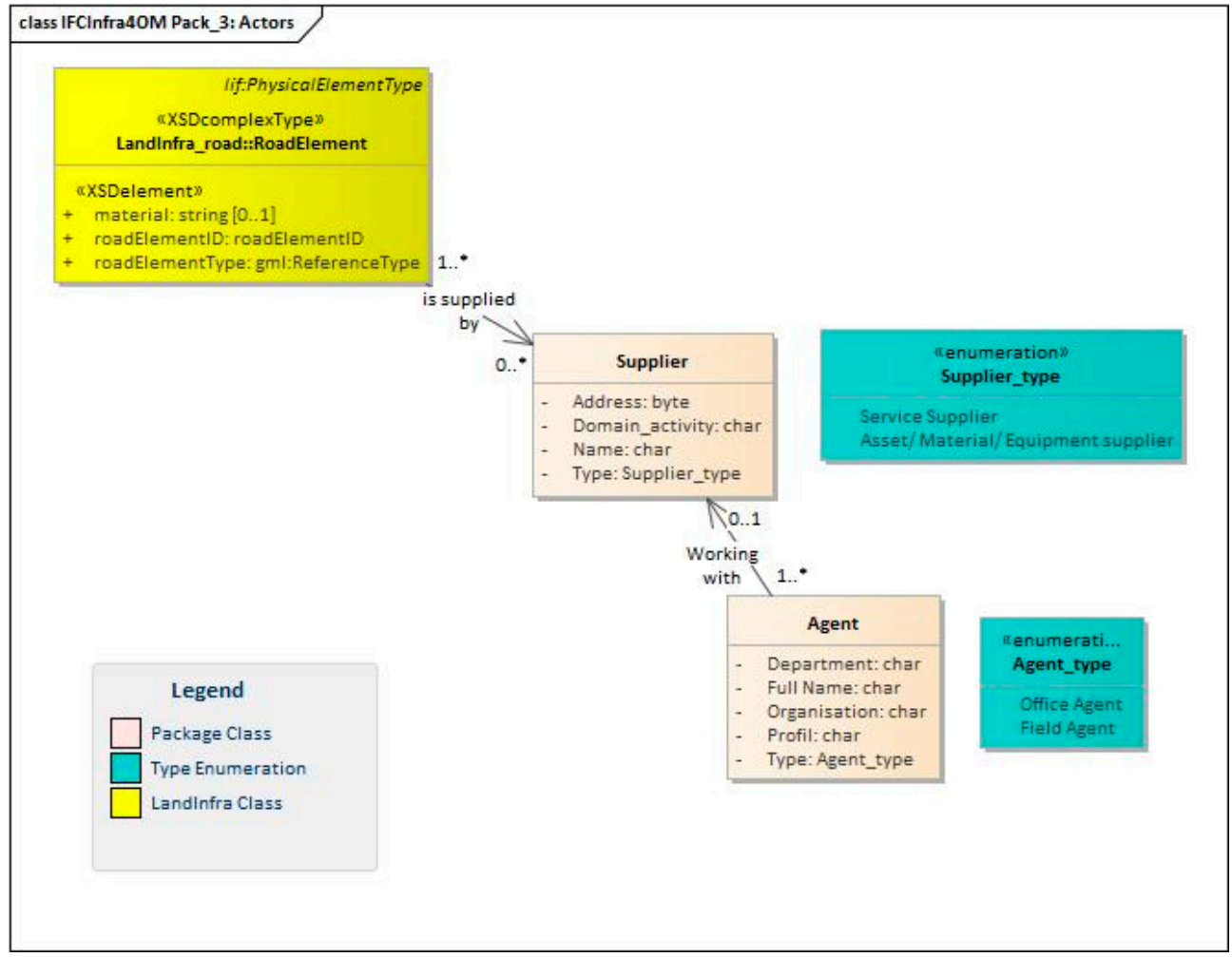

(c)

Figure 5. (a). IFCInfra4OM Data Model: Operation Package. (b). IFCInfra4OM Data Model: Monitoring Package. (c). IFCInfra4OM Data Model: Actor Package.

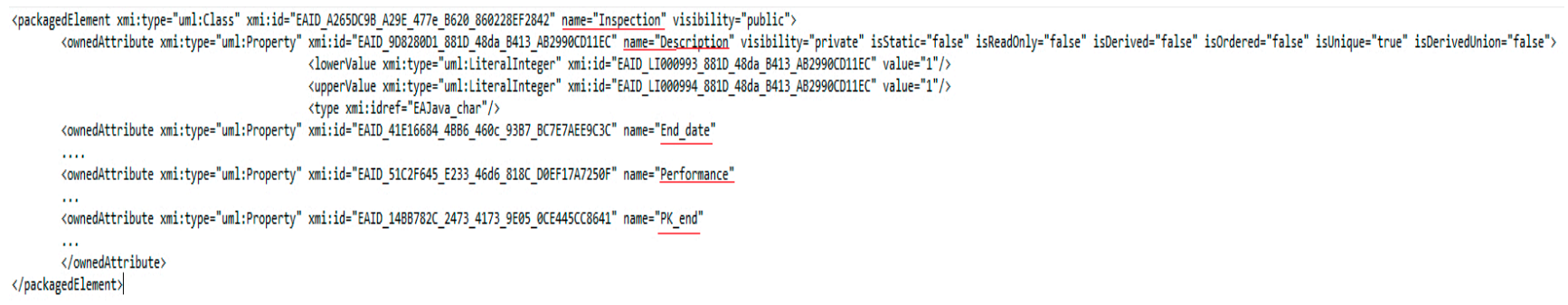

Figure 6. Extract from XML Writing of Class “Inspection”.

\section{Results}

\subsection{Presentation of the Case Study}

The case study concerns the A7 Highway in Morocco that links the cities of Agadir and Marrakech. It is characterised by a slope located at the level of the High Atlas Mountains at the 350 kilometric point, $25 \mathrm{~km}$ south of the Zaouiat Ait Mellal tunnel in the Foum Jrana zone $[62,63]$. Its central zone is located at $30^{\circ} 59^{\prime} 10.32^{\prime \prime} \mathrm{N}, 9^{\circ} 02^{\prime} 28.10^{\prime \prime} \mathrm{W}$. The geographical extent of the area is illustrated in Figure 7. Examples of operations conducted on this highway section in accordance with the IFCInfra4OM model are shown in Table 7.

The slope studied extends over $1200 \mathrm{~m}$ and is $110 \mathrm{~m}$ in height [62]. It is characterised by several instabilities that present a danger to highway users. These instabilities are [63]:

(1) Presence of a fault in N130 direction and a dip of $20^{\circ}$ to the North-East giving rise to a landslide.

(2) Fracturing of the rock mass and unstable rock masses at the central level. This led to a collapse at the level of some berms. 
(3) Presence of isolated boulders on the natural slope. They are characterised by a precarious balance and are likely to detach.

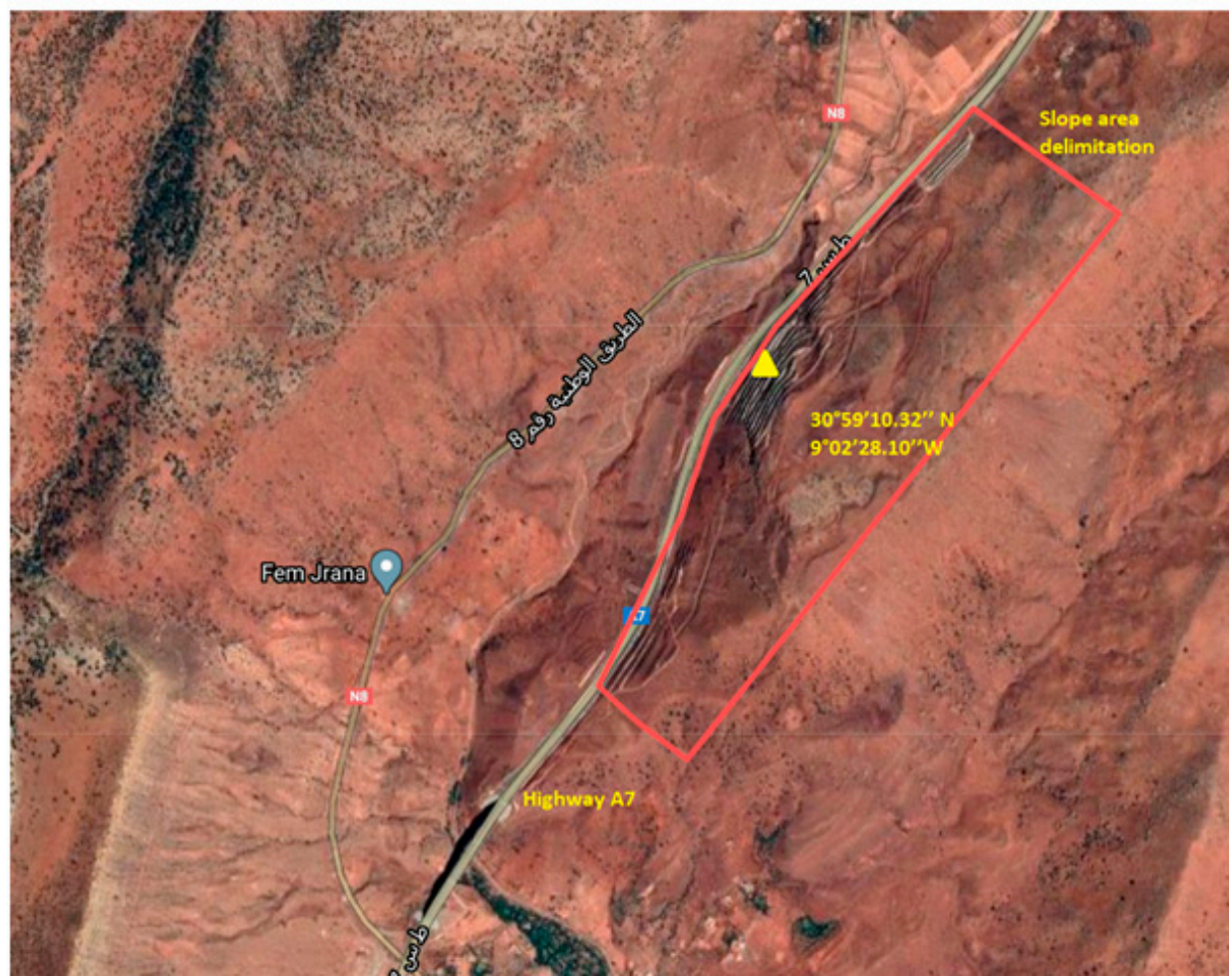

Figure 7. A7 Agadir-Marrakech Moroccan highway geographic area studied.

Table 7. Examples of Operations Completed on the A7 Highway Slope.

\begin{tabular}{|c|c|c|}
\hline \multicolumn{3}{|c|}{ "Operation" Class } \\
\hline Description & Status & Type \\
\hline Installation of dynamic barriers to stop falling rocks on the roadway & Completed & Realisation \\
\hline Installation of a 3-level gabion wall in the intermediate zone & Completed & Realisation \\
\hline Reinforcement of the existing slope by nailing and shotcrete & Completed & Reparation \\
\hline
\end{tabular}

Three types of equipment are installed on the surface of the slope to remedy the hazards observed relating to landslides and rocky massifs (see Figure 8). This equipment was modelled on the Highway 3D model as shown in Figure 9.

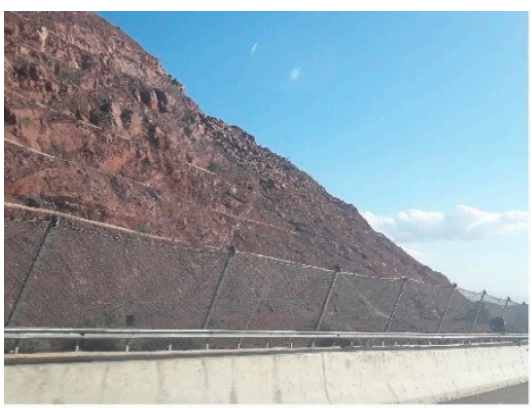

a

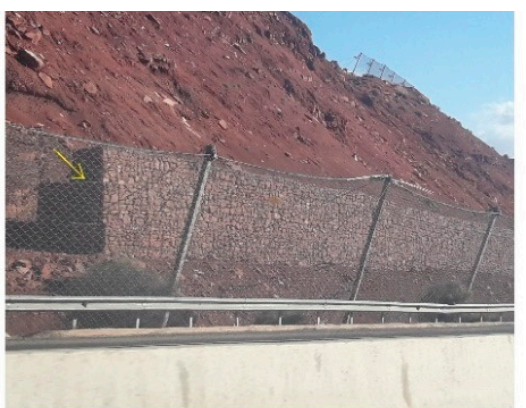

b

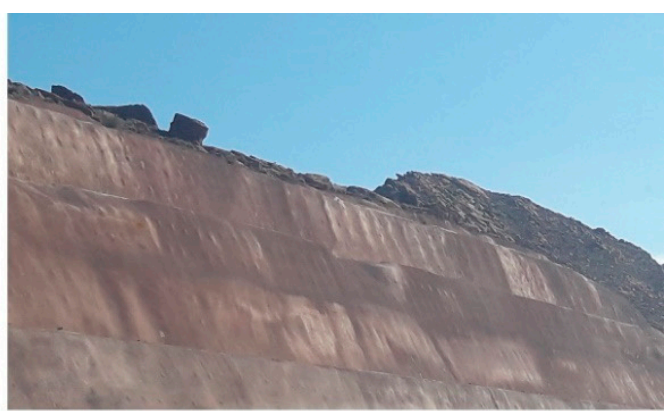

C

Figure 8. Security Equipment installed on the slope: (a) Dynamic barrier, (b) Gabion wall, (c) Shotcrete berms. 


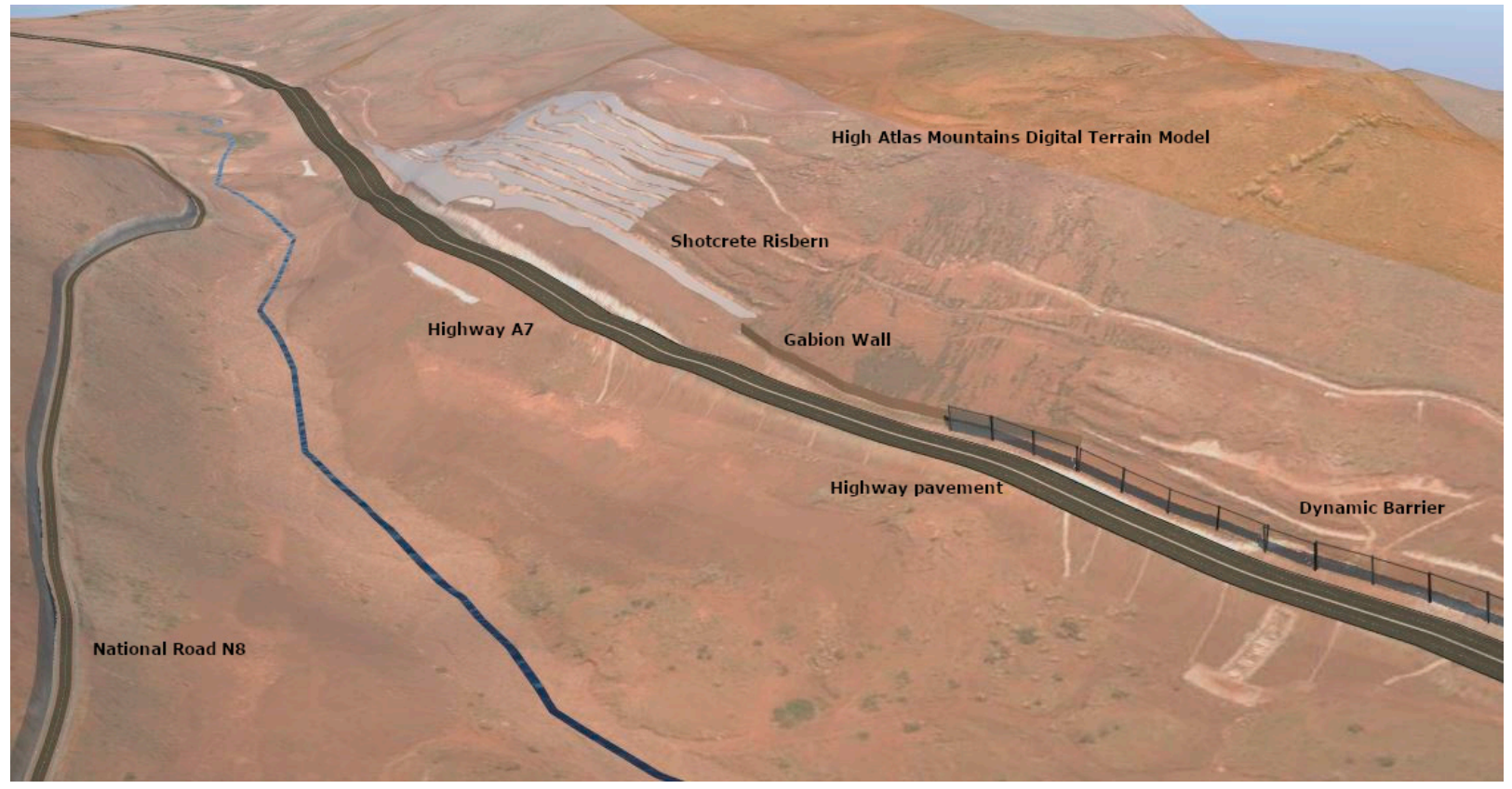

Figure 9. Highway 3D Model: studied segment of A7 Moroccan Highway (Infraworks software).

\subsection{IFCInfra4OM Implementation}

The purpose of the case study validation is to implement the IFCInfra4OM data model to a real highway infrastructure to illustrate the adaptability of this ontology and give authenticate the concept. The implementation methodology is shown in Figure 10.

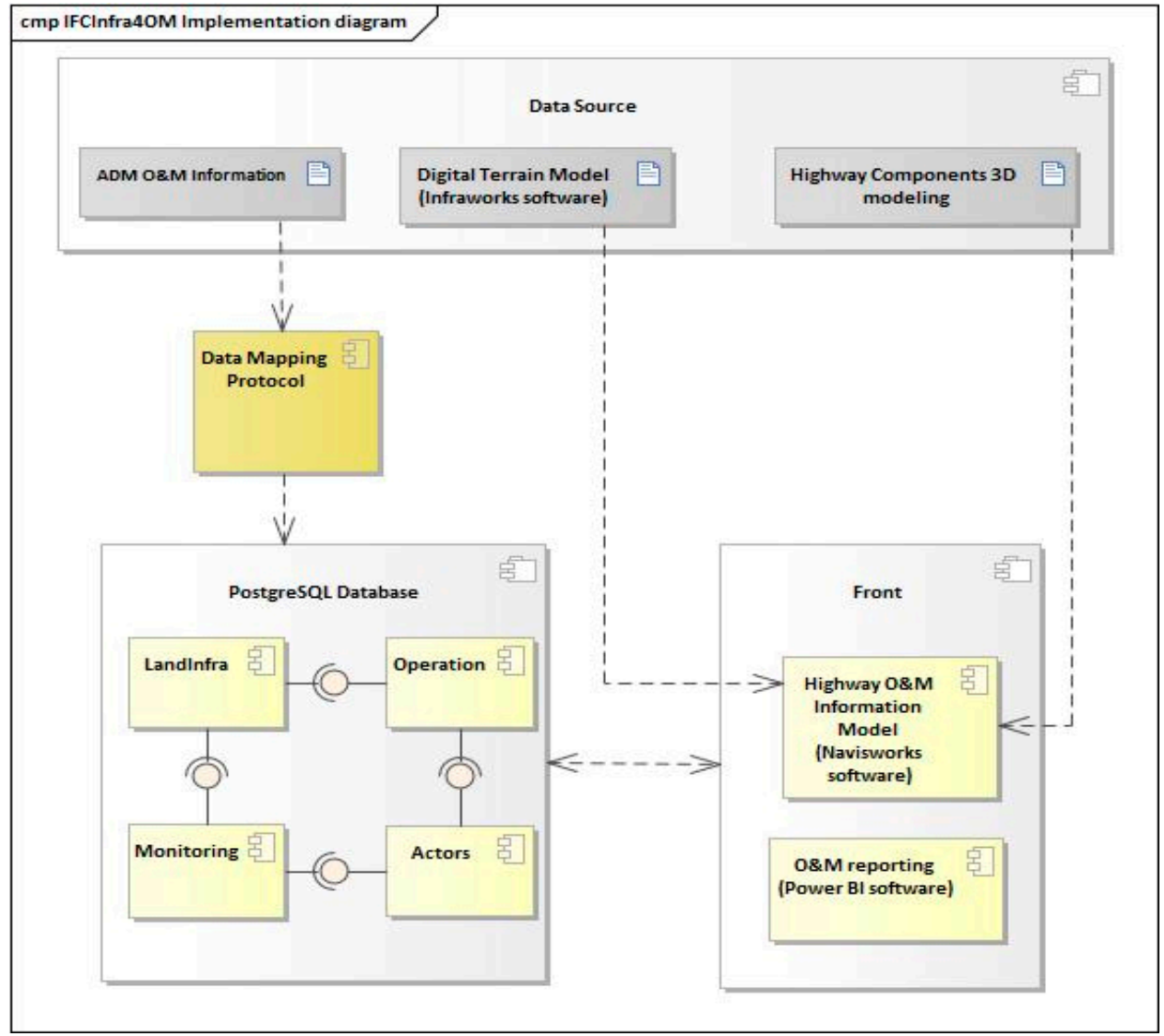

Figure 10. IFCInfra4OM Case Study Implementation Diagram. 
The implementation is done in three steps:

(1) First, a package diagram (Figure 11) is realised to illustrate the IFCInfra4OM data model structure. The model is divided into four packages to allow practical use and future software development. These packages concern O\&M management, monitoring system, actor's management system and highway components. This latter is replaced in the case study with LandInfra standard model to enable a first implementation.

(2) Then, a 3D Model of the studied highway was established. This model is used to connect the data base and produce the highway information model for O\&M management (see Figure 9).

(3) Finally, a database is developed based on the IFCInfra4OM data model. This database is sustained by data from the case study then linked to a $3 \mathrm{D}$ viewer to enable use cases scenarios.

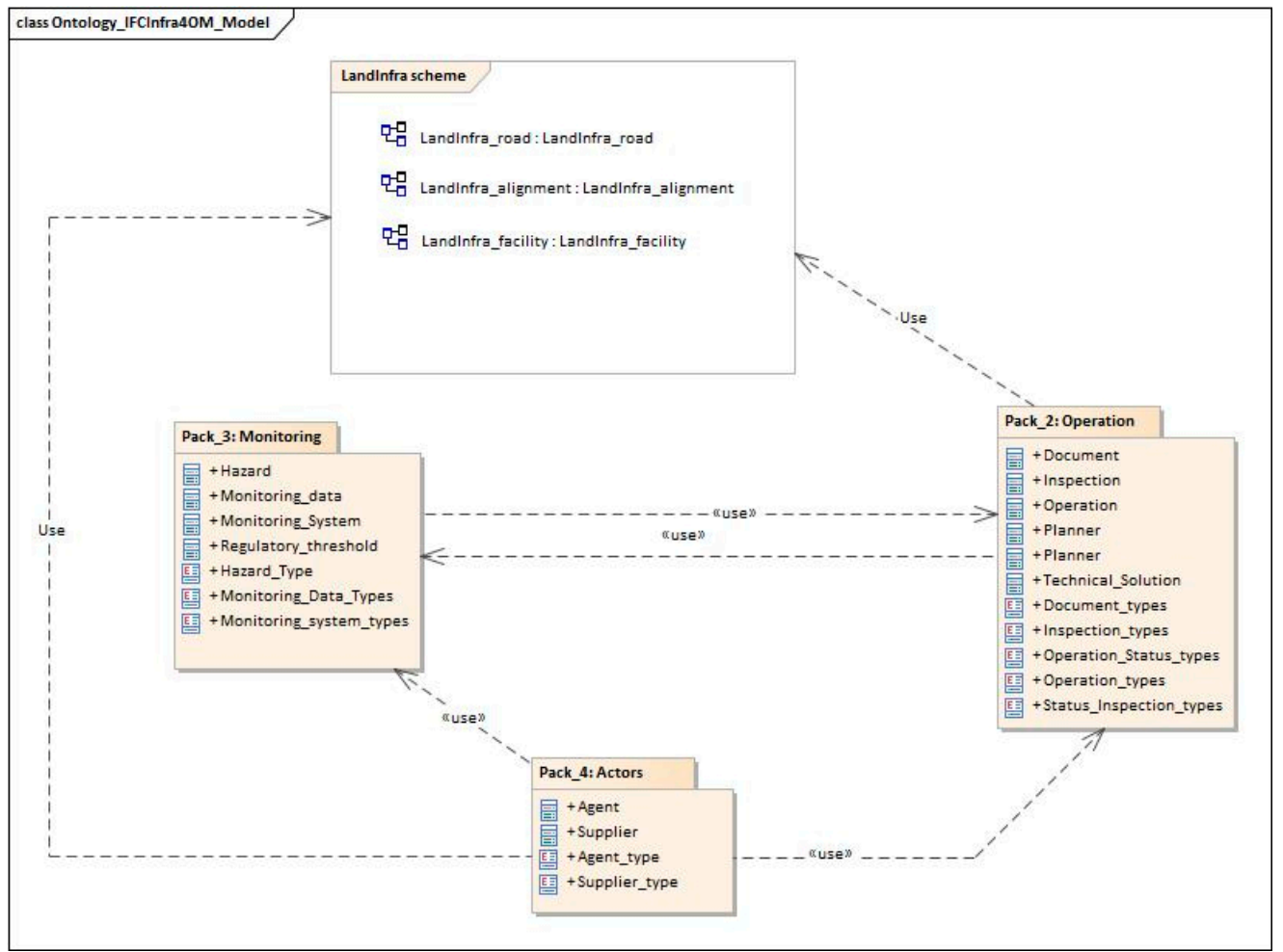

Figure 11. IFCInfra4OM Packages Diagram.

A database (DB) is generated from the IFCInfra4OM conceptual model (see Figure 12). With a data mapping protocol, the information required by the UML class diagram as well as the links to the highway segment concerned by the O\&M activities are integrated from the DB to the 3D model.

Two use cases are investigated. First, 3D visualisation (see Figure 13) of the highway information model gives O\&M a geospatial context. Operations and inspections can be recognised by both semantic description and geographic location. Moreover, it helps understand the impact of O\&M results on the highway environment. Then, O\&M reporting is established (see Figure 14). The report integrates: (1) an extract table of information regarding the highway examined, the maintenance operations conducted, and the equipment installed; (2) diagrams describing the performance and statistics about operations; and (3) a map to geographically locate the operations effectuated. 


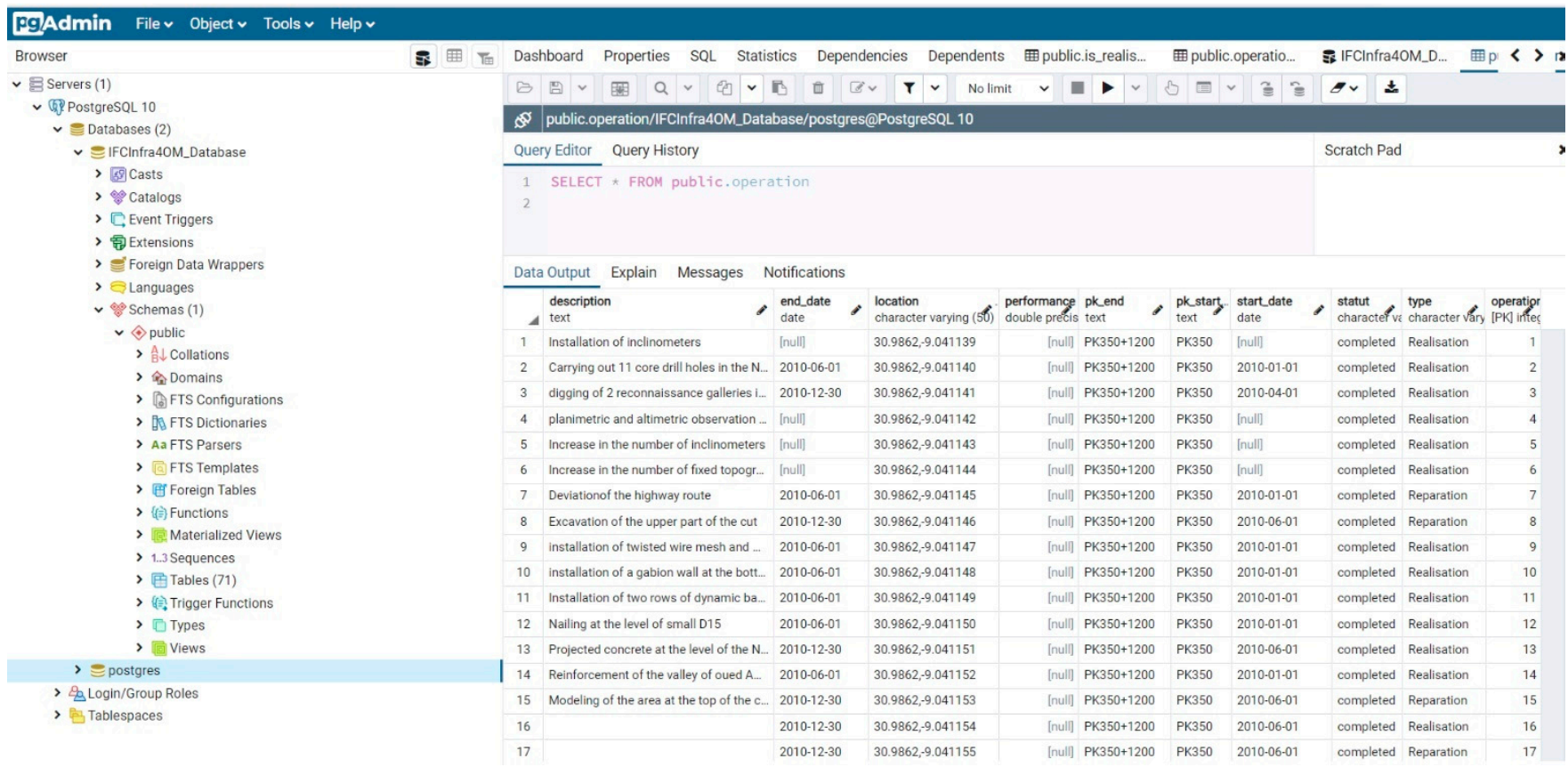

Figure 12. IFCInfra4OM Database Extract (PostgreSQL Database).

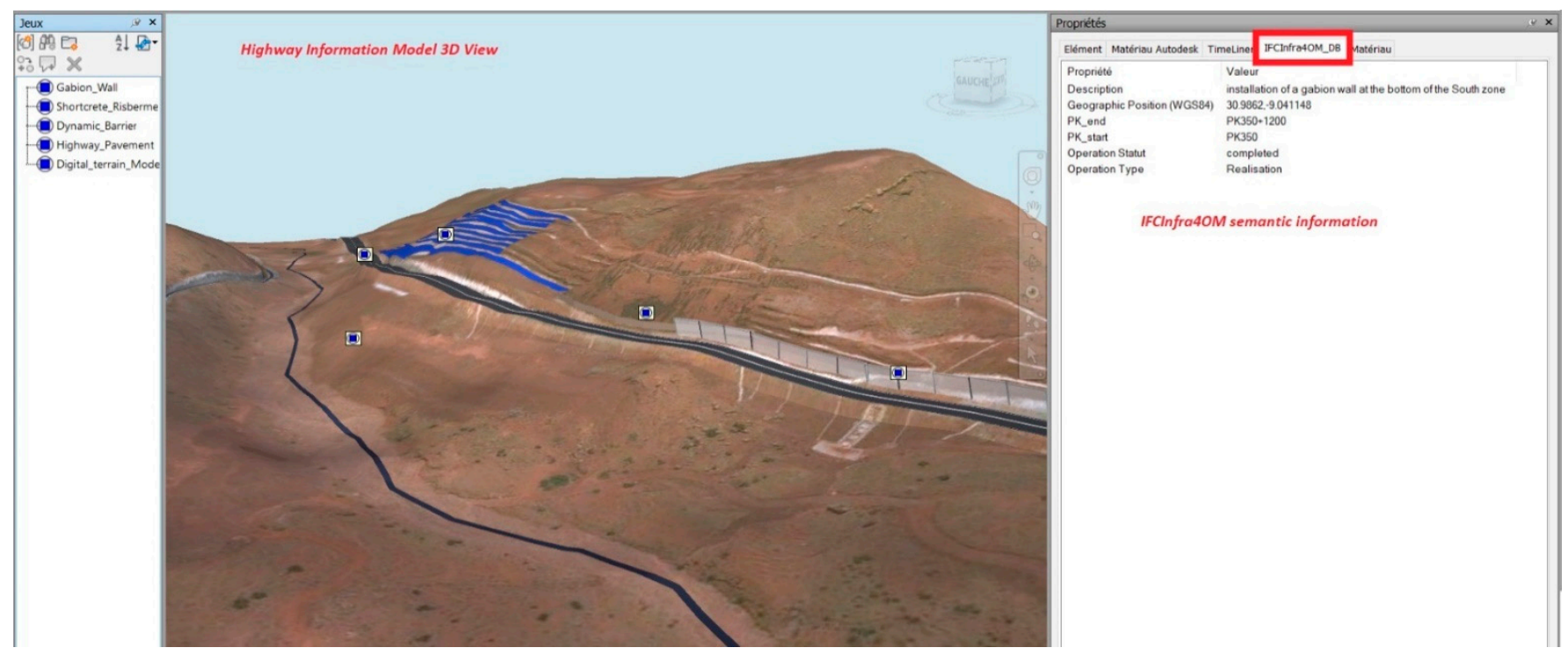

Figure 13. Use Case 1: 3D Visualization of the Highway O\&M Information Model (Navisworks software).

\subsection{Results Validation}

\subsubsection{Semantic Validation}

The definition of the process and the semantic validation of the IFCInfra $4 \mathrm{OM}$ data model is achieved through experts assistance from the Moroccan establishment, Moroccan Highway Academy (ADM Academy).

The purpose of experts verification is to analyse and evaluate the concepts of ontology based on several criteria [68], namely: (1) accuracy; (2) completeness; (3) conciseness; (4) coherence, and (5) organisational fitness. 


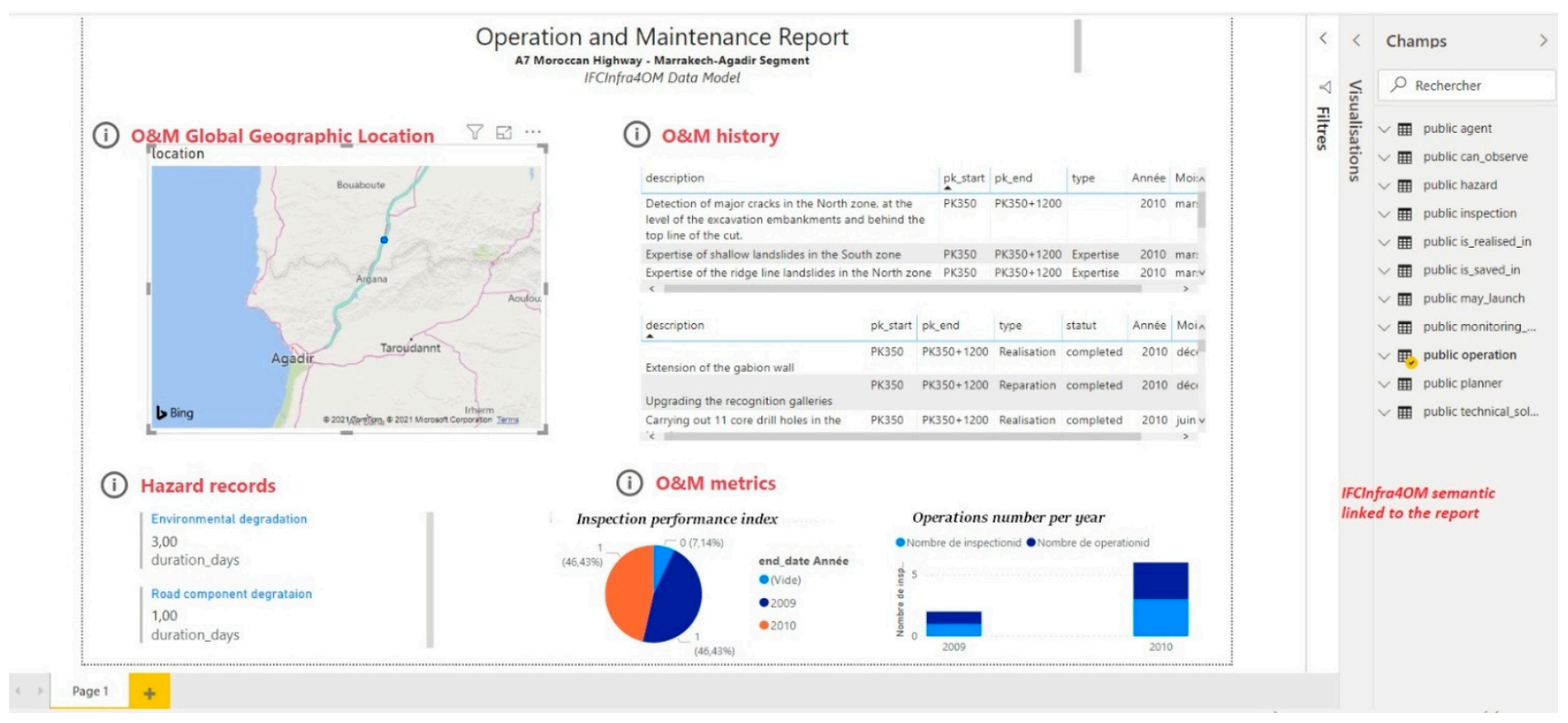

Figure 14. Use Case 2: O\&M Reporting Based on IFCInfra4OM Data Model (Power BI software).

\subsubsection{Syntactic Validation}

The consistency and instantiation of the model is verified via the transcription of the ontology in XML. A reasoner integrated into the modelling software made it possible to automate the verification of this syntax and the results are elaborated in Table 8.

Table 8. IFCInfra4OM Syntactical Validation Results.

\begin{tabular}{lll}
\hline Validation Step & & \multicolumn{1}{c}{ Validation Rule } \\
\hline & Well-formedness of entities and relationships: \\
& $\checkmark$ & Checks if elements are valid UML2.5 elements. \\
& $\checkmark$ & Element Composition validation: \\
Validation of UML model & $\checkmark$ & Checks validity of children \\
& $\checkmark$ & Checks the right number of valid children \\
& Property Validity: \\
& $\checkmark$ & Checks correctness of UML property type. \\
& $\checkmark$ & Validates property values. \\
& $\checkmark$ & Checks for conflicting values. \\
& XML grammar compliant declaration of: \\
& $\checkmark$ & entities and data types \\
Validation of XML model & $\checkmark$ & enumerations \\
& $\checkmark$ & attributes of entities \\
& $\checkmark$ & domain rules and uniqueness rules \\
\hline
\end{tabular}

\section{Extending IFC Standard Overview}

For the IFC Standard enrichment by the ontology IFCInfra4OM, we propose the diagram in Figure 15. The concepts, about the components of the highway, and which are borrowed from the LandInfra standard in the presented case study, will be replaced by those of the IFCRoad following appropriate procedures. Indeed, the extension of the IFC standard is based on specific relationship classes [69]. 


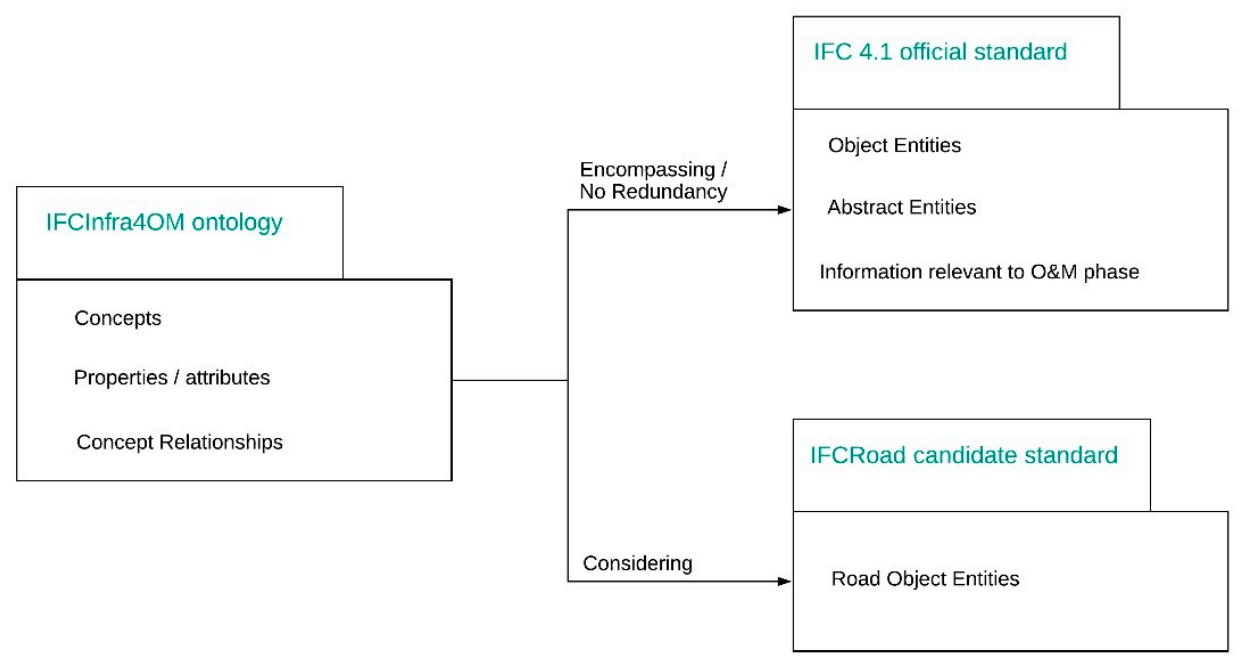

Figure 15. Extending Mechanism Proposed to Integrate IFCInfra4OM within IFC Schema.

\section{Conclusions and Discussion}

This paper presents an ontological approach to integrate information from the O\&M phase in a BIM for highways. This approach aims to set up a framework of concepts necessary for the reuse of the proposed data model either to integrate it into BIM or to use it on other facility management systems.

The literature review helps understand the existing transport infrastructures management systems. BIM is one of those systems with the additional advantage of combining information with 3D rendering for a better understanding of an infrastructure project. It also allows to establish the main information requirements for an optimal management of the O\&M phase of transport infrastructure. Moreover, it provides an overview of the efforts made in the research world to integrate O\&M into BIM. Finally, it underlines the main issues of O\&M information integration issues in BIM standard.

The methodology used in this paper details how the proposed IFCInfra4OM ontology remedy the main problems encountered in managing an infrastructure in its O\&M phase through BIM. This paper provides a proof of concept by modelling the proposed ontology and directly linking its data model to a 3D model of a segment on the A7 Agadir-Marrakech highway in Morocco to build a Highway Information Model.

The case study presented enables the application of some use cases of BIM to this highway. It also helps understand how the IFCIfra4OM bridges the gaps detected in the literature review. The implementation of IFCInfra $4 \mathrm{OM}$ on real world data demonstrates that:

1. Hierarchical modelling of O\&M data enables several analyses. Such complex analyses are not yet possible with the unstructured O\&M information in the current IFC version. Examples of this analyses established in this paper, through the case study, are: (a) multicriteria analysis to extract information useful to the user such as the calculation of performance over time; (b) data combinations to allow statistics such as hazards recordings consistent to their types.

2. IFCInfra $4 \mathrm{OM}$ is expandable to be integrated in the IFC schema. The criteria adopted to define concepts allows the modelling of several object classes that are interoperable with IFCRoad.

In future research work, the extension of the IFC standard will be conducted based on the practices published by BuildingSmart. The objective is to create a standardised highway information model for a full management of its O\&M phase.

The IFCInfra $4 \mathrm{OM}$ ontology data model submitted in this paper is a tool for the standardisation of O\&M for road infrastructure BIM. However, and in order to make this system more practical on the macro level and reduce the research gap regarding the integration of BIM into infrastructures O\&M, we recommend the following research horizons: (1) A reflection of this model to make it suitable for infrastructures in general 
while keeping its universal aspect in order to allow the IFC extension; (2) An automation of monitoring data integration from 3D survey sources such as 3D laser scanners and drones; (3) A development of systems that allow the real-time use of these data by layering it on a BIM model.

Author Contributions: Conceptualization, Sara Ait-Lamallam; Methodology, Sara Ait-Lamallam, Imane Sebari and Reda Yaagoubi; Software, Sara Ait-Lamallam; Validation, Imane Sebari, Reda Yaagoubi and Omar Doukari; Writing — original draft, Sara Ait-Lamallam; Writing—review \& editing, Imane Sebari, Reda Yaagoubi and Omar Doukari. All authors have read and agreed to the published version of the manuscript.

Funding: This research received no external funding.

Institutional Review Board Statement: Not applicable.

Informed Consent Statement: Not applicable.

Data Availability Statement: Publicly available datasets were analysed in this study. This data can be found here: (1) for Digital Terrain Model input of the 3D model presented in the case study [Infraworks Model Builder Database]; (2) for O\&M information applied to the case study [62,63] in References section.

Acknowledgments: The authors thank the support of the Moroccan Highways Academy (ADM ACADEMY). Special thanks to MEQUEDADE Nabil, Development Director at ADM ACADEMY, for his insightful assistance and support.

Conflicts of Interest: The authors declare no conflict of interest.

\section{References}

1. Bradley, A.; Li, H.; Lark, R.; Dunn, S. BIM for Infrastructure: An Overall Review and Constructor Perspective. Autom. Constr. 2016, 71, 139-152. [CrossRef]

2. Azhar, S.; Khalfan, M.; Maqsood, T. Building Information Modeling (BIM): Now and Beyond. Australas. J. Constr. Econ. Build. 2012, 12, 15-18.

3. Soibelman, L.; Wu, J.; Caldas, C.; Brilakis, I.; Lin, K.-Y. Management and Analysis of Unstructured Construction Data Types. Adv. Eng. Inf. 2008, 22, 15-27. [CrossRef]

4. Hijdra, A.; Anagnostopoulou, A.; Marcovaldi, E.; Pasquali, F.; Mbah, N. Living Lab for Three Real Life Situations (Cross-Asset, Cross-Ifc, Cross-Border). Technical Report, AM4INFRA 2018. Available online: http://www.am4infra.eu/download/public reports/D-1.3-Living-Labs-FINAL-.pdf (accessed on 16 February 2021).

5. Tang, N.; Hu, H.; Xu, F.; Zhu, F. Personalized Safety Instruction System for Construction Site Based on Internet Technology. Saf. Sci. 2019, 116, 161-169. [CrossRef]

6. Eastman, C.; Teicholz, P.; Sacks, R.; Liston, K. BIM Handbook: A Guide to Building Information Modelling for Owners, Managers, Designers. In Engineers and Contractors, 2nd ed.; Eastman, C.M., Ed.; Wiley: Hoboken, NJ, USA, 2011; ISBN 978-0-470-54137-1.

7. Joseph, J. BIM Titles and Job Descriptions: How Do They Fit in Your Organizational Structure? 2011. Available online: https: / / fliphtml5.com/mrla/iucv/basic (accessed on 15 December 2020).

8. Röck, M.; Hollberg, A.; Habert, G.; Passer, A. LCA and BIM: Visualization of Environmental Potentials in Building Construction at Early Design Stages. Build. Environ. 2018, 17, 153-161. [CrossRef]

9. Mirzaei, A.; Nasirzadeh, F.; Jalal, M.P.; Zamani, Y. 4D-BIM Dynamic Time-Space Conflict Detection and Quantification System for Building Construction Projects. J. Constr. Eng. Manag. 2018, 14, 04018056. [CrossRef]

10. McArthur, J.J. A Building Information Management (BIM) Framework and Supporting Case Study for Existing Building Operations, Maintenance and Sustainability. Procedia Eng. 2015, 8, 1104-1111. [CrossRef]

11. Borrmann, A.; König, M.; Koch, C.; Beetz, J. Building Information Modelling: Technology Foundations and Industry Practice; Springer: Berlin/Heidelberg, Germany, 2018. [CrossRef]

12. Digital Transition Plan for Buildings (PTNB). European Construction Sector Observatory 2018. Available online: https://ec. europa.eu/docsroom/documents/29806/attachments/6/translations/en/renditions/native (accessed on 16 February 2021).

13. ISO 16739-1:2018 Industry Foundation Classes (IFC) for Data Sharing in the Construction and Facility Management IndustriesPart 1: Data Schema. Available online: https:/ /www.iso.org/standard/70303.html (accessed on 7 April 2021).

14. BuildingSmart International. Industry Foundation Classes (IFC). Available online: https://www.buildingsmart.org/standards/ bsi-standards/industry-foundation-classes/ (accessed on 23 April 2021).

15. Matějka, P. The importance of a transport infrastructure construction for the implementation of BIM. In Proceedings of the People, Buildings and Environment 2014, An International Scientific Conference, Kroměřǐž, Czech Republic, 15-17 October 2014; pp. 277-287. Available online: https://www.fce.vutbr.cz/ekr/pbe/Proceedings/2014/027_14174.pdf (accessed on 24 April 2021). 
16. Zou, Y.; Kiviniemi, A.; Jones, S.W.; Walsh, J. Risk Information Management for Bridges by Integrating Risk Breakdown Structure into 3D/4D BIM. KSCE J. Civ. Eng. 2019, 23, 467-480. [CrossRef]

17. Fabozzi, S.; Biancardo, S.A.; Veropalumbo, R.; Bilotta, E. I-BIM Based Approach for Geotechnical and Numerical Modelling of a Conventional Tunnel Excavation. Tunn. Undergr. Space Technol. 2021, 108, 103723. [CrossRef]

18. Tang, F.; Ma, T.; Zhang, J.; Guan, Y.; Chen, L. Integrating three-dimensional road design and pavement structure analysis based on BIM. Autom. Constr. 2020, 113, 103152. [CrossRef]

19. Borrmann, A.; Muhic, S.; Hyvärinen, J.; Chipman, T.; Jaud, S.; Castaing, C.; Dumoulin, C.; Liebich, T.; Mol, L. The IFC-Bridge Project-Extending the IFC Standard to Enable High-Quality Exchange of Bridge Information Models. In Proceedings of the 2019 European Conference on Computing in Construction, Chania, Greece, 10-12 July 2019; pp. 377-386. [CrossRef]

20. Jetlund, K.; Onstein, E.; Huang, L. IFC Schemas in ISO/TC 211 Compliant UML for Improved Interoperability between BIM and GIS. ISPRS Int. J. Geo-Inf. 2020, 9, 278. [CrossRef]

21. Heaton, J.; Parlikad, A.K.; Schooling, J. Design and Development of BIM Models to Support Operations and Maintenance. Comput. Ind. 2019, 111, 172-186. [CrossRef]

22. Ghalenoeei, N.; Saghatforoush, E.; Athari Nikooravan, H.; Preece, C. Evaluating Solutions to Facilitate the Presence of Operation and Maintenance Contractors in the Pre-Occupancy Phases: A Case Study of Road Infrastructure Projects. Int. J. Constr. Manag. 2021, 21, 140-152. [CrossRef]

23. Whole Building Design Guide. Facilities Operation \& Maintenance. Available online: http://www.wbdg.org/om/om.php (accessed on 16 February 2021).

24. Pelzeter, A. Building Optimisation with Life Cycle Costs-The Influence of Calculation Methods. J. Facil. Manag. 2007, 5, 115-128. [CrossRef]

25. Nawi, M.N.M.; Radzuan, K.; Salleh, N.A.; Ibrahim, S.H. Value management: A strategic approach for reducing faulty design and maintainability issue in IBS building. Adv. Environ. Biol. 2014, 8, 1859-1863.

26. Alexander, D. Towards the Development of a Standard in Emergency Planning. Disaster Prev. Manag. 2005, 14, 158-175. [CrossRef]

27. Lu, Q.; Chen, L.; Lee, S.; Zhao, X. Activity Theory-Based Analysis of BIM Implementation in Building O\&M and First Response. Autom. Constr. 2018, 85, 317-332. [CrossRef]

28. Chunkhare, M.; Jadhav, D.; Ghare, A.; Ghare, V. Designing and Developing a Computerized Medical Gear's Recording System. Int. J. Mod. Agric. 2020, 9, 7.

29. Conrol Services. What Is Building Automation. Available online: http://www.controlservices.com/learning_automation.htm (accessed on 16 February 2021).

30. Maier, D.; Vadastreanu, A.M.; Keppler, T.; Eidenmuller, T.; Maier, A. Innovation as a Part of an Existing Integrated Management System. Procedia Econ. Financ. 2015, 26, 1060-1067. [CrossRef]

31. Drabicki, A.; Kucharski, R.; Cats, O.; Szarata, A. Modelling the Effects of Real-Time Crowding Information in Urban Public Transport Systems. Transp. A Transp. Sci. 2021, 17, 675-713. [CrossRef]

32. Sodagaran, A.; Zarei, N.; Azimifar, Z. Intelligent Traffic Information System a Real-Time Traffic Information System on the Shiraz Bypass. Matec. Web Conf. 2016, 81, 04003. [CrossRef]

33. Asaul, A.; Malygin, I.; Komashinskiy, V. The Project of Intellectual Multimodal Transport System. Transp. Res. Procedia 2017, 20, 25-30. [CrossRef]

34. Casady, C.B.; Eriksson, K.; Levitt, R.E.; Scott, W.R. (Re)Defining Public-Private Partnerships (PPPs) in the New Public Governance (NPG) Paradigm: An Institutional Maturity Perspective. Public Manag. Rev. 2020, 22, 161-183. [CrossRef]

35. Vilutienė, T.; Šarkienè, E.; Šarka, V.; Kiaulakis, A. BIM Application in Infrastructure Projects. Baltic J. Road Bridge Eng. 2020, 15, 74-92. [CrossRef]

36. Yin, X.; Liu, H.; Chen, Y.; Wang, Y.; Al-Hussein, M. A BIM-Based Framework for Operation and Maintenance of Utility Tunnels. Tunn. Undergr. Space Technol. 2020, 97, 103252. [CrossRef]

37. Aziz, Z.; Riaz, Z.; Arslan, M. Leveraging BIM and Big Data to Deliver Well Maintained Highways. Facilities 2017, 35, 818-832. [CrossRef]

38. Shalabi, F.; Turkan, Y. IFC BIM-Based Facility Management Approach to Optimize Data Collection for Corrective Maintenance. J. Perform. Constr. Facil. 2017, 31, 04016081. [CrossRef]

39. Huang, A.L.; Chapman, R.E.; Butry, D.T. Metrics and Tools for Measuring Construction Productivity: Technical and Empirical Considerations. Available online: https://tsapps.nist.gov/publication/get_pdf.cfm?pub_id=903603 (accessed on 16 February 2021).

40. Park, C.-S.; Lee, D.-Y.; Kwon, O.-S.; Wang, X. A Framework for Proactive Construction Defect Management Using BIM, Augmented Reality and Ontology-Based Data Collection Template. Autom. Constr. 2013, 33, 61-71. [CrossRef]

41. Fanning, B.; Clevenger, C.M.; Ozbek, M.E.; Mahmoud, H. Implementing BIM on Infrastructure: Comparison of Two Bridge Construction Projects. Pract. Period. Struct. Des. Constr. 2015, 20, 04014044. [CrossRef]

42. Cheng, J.C.P.; Lu, Q.; Deng, Y. Analytical Review and Evaluation of Civil Information Modelling. Autom. Constr. 2016, 67, 31-47. [CrossRef]

43. Borrmann, A.; König, M.; Koch, C.; Beetz, J. Building Information Modelling: Why? What? How? In Building Information Modelling; Borrmann, A., König, M., Koch, C., Beetz, J., Eds.; Springer International Publishing: Cham, Switzerland, 2018; pp. 1-24, ISBN 978-3-319-92861-6. 
44. Motawa, I.; Almarshad, A. A Knowledge-Based BIM System for Building Maintenance. Autom. Constr. 2013, $29,173-182$. [CrossRef]

45. Wang, Y.; Wang, X.; Wang, J.; Yung, P.; Jun, G. Engagement of Facilities Management in Design Stage through BIM: Framework and a Case Study. Adv. Civ. Eng. 2013, 2013,1-8. [CrossRef]

46. Ryu, D.-W.; Kim, J.I.; Suh, S.; Suh, W. Evaluating Risks Using Simulated Annealing and Building Information Modelling. Appl. Math. Model. 2015, 39, 5925-5935. [CrossRef]

47. Chen, L.; Lu, S.; Zhao, Q. Research on BIM-Based Highway Tunnel Design, Construction and Maintenance Management Platform. IOP Conf. Ser. Earth Environ. Sci. 2019, 218, 012124. [CrossRef]

48. Hamledari, H.; Azar, E.; McCabe, B. IFC-Based Development of As-Built and As-Is BIMs Using Construction and Facility Inspection Data: Site-to-BIM Data Transfer Automation. J. Comput. Civ. Eng. 2018, 32, 04017075. [CrossRef]

49. International Organisation for Standardization: ISO 29481-1:2010 Building Information Modelling-Information Delivery Manual-Part 1: Methodology and Format. Available online: https://www.iso.org/standard/45501.html (accessed on 16 February 2021).

50. BuildingSmart International. Infrastructure Room. Available online: https://www.buildingsmart.org/standards/rooms/ infrastructure/ (accessed on 16 February 2021).

51. Kim, C.; Kwon, S.; You, S.; Lim, J. Using Information Delivery Manual (IDM) for Efficient Exchange of Building Design Information. In Proceedings of the 27th ISARC, Bratislava, Slovakia, 25-27 June 2010.

52. Floros, G.S.; Boyes, G.; Owens, D.; Ellul, C. Developing IFC for Infrastructure: A Case Study of three Highway entities. ISPRS Ann. Photogramm. Remote Sens. Spat. Inf. Sci. 2019, IV-4/W8, 59-66. [CrossRef]

53. IFC 4.3 RC2-Release Candidate 2. Scope, General Usage. Available online: https://standards.buildingsmart.org/IFC/DEV/IFC4 3/RC2/HTML/ (accessed on 7 April 2021).

54. Wong, J.K.W.; Ge, J.; He, S.X. Digitisation in facilities management: A literature review and future research directions. Autom. Constr. 2018, 92, 312-326. [CrossRef]

55. BuildingSmart International. IFC $2 \times 3$, IFCFACILITIESMGMTDOMAIN. Available online: https:/ / standards.buildingsmart org/IFC/RELEASE/IFC2\$ times\$3/TC1/HTML/ifcfacilitiesmgmtdomain/ifcfacilitiesmgmtdomain.htm (accessed on 7 April 2021).

56. Smith, B. Ontology. In Blackwell Guide to the Philosophy of Computing and Information; Floridi, L., Ed.; Blackwell Philosophy Guides; Blackwell Pub: Malden, MA, USA, 2004; ISBN 978-0-631-22918-6.

57. International Organisation for Standardization: ISO 55000:2014, Asset Management—Overview, Principles and Terminology. Available online: https:/ /www.iso.org/standard/55088.html (accessed on 16 February 2021).

58. BSI Group. British Standards Institution Specification for Information Management for the Operational Phase of Assets Using Building Information Modelling: Incorporating Corrigendum No. 1; BSI Group: London, UK, 2014; ISBN 978-0-580-86674-6.

59. EUROTL Framework Overview. Available online: https://www.roadotl.eu/static/eurotl-ontologies/index.html (accessed on 16 February 2021).

60. Jackson, P. Infrastructure Asset Managers BIM Requirements 2018. Available online: https://www.buildingsmart.org/wpcontent/uploads /2018/01/18-01-09-AM-TR1010.pdf (accessed on 16 February 2021).

61. Autoroute Du Maroc. PRS RE1 PRO02-01 0513 Pour le Suivi des Grands Ouvrages de Terrassement Déblais a Risque. (unpublished).

62. Hemri, K.; Mounji, Y.; Labied, H. Stabilisation de Talus Rocheux. In Les Instabilités des Talus, 47-60. Available online: https://admacademie.ma/sites/default/files/instabilites_des_talus.pdf (accessed on 16 February 2021).

63. Benguebour, M.H.; Debbarh, M.A. Stabilisation du Déblai 15 de L'autoroute Marrakech-Agadir. 2014. Available online: https: / / docplayer.fr/111952436-Stabilisation-du-deblai-15-de-l-autoroute-marrakech-agadir.html (accessed on 16 February 2021).

64. Zahayer, Y.; Lheureux, C. Le BIM Pour la Construction Autoroutière 2020. 70. Available online: https://www.hexabim.com/ theses-bim/le-bim-pour-la-construction-autoroutiere (accessed on 16 February 2021).

65. Lakhda, S.; Lheureux, C. Projets Autoroutiers au Maroc: Le Bim Comme Outil d'aide a L'exploitation et a la Communication 2020. Available online: https:/ / www.hexabim.com/theses-bim/projets-autoroutiers-au-maroc-le-bim-comme-outil-d-aide-a1-exploitation-et-a-la-communication (accessed on 16 February 2021).

66. Open Geospatial Consortium. Land and Infrastructure (LandINfra). Available online: https://www.ogc.org/standards/landinfra (accessed on 16 February 2021).

67. Kivits, R.A.; Furneaux, C. BIM: Enabling Sustainability and Asset Management through Knowledge Management. Sci. World J. 2013, 2013, 1-14. [CrossRef]

68. Denny, V. Ontology Validation. Available online: https:/ / publikationen.bibliothek.kit.edu/1000018419/1355289 (accessed on 16 February 2021).

69. Theiler, M.; Smarsly, K. IFC Monitor-An IFC Schema Extension for Modelling Structural Health Monitoring Systems. Adv. Eng. Inform. 2018, 37, 54-65. [CrossRef] 